TAO, Vol. 11, No. 4, 833-860, December 2000

\title{
Interannual Variation of the Asian-Pacific Atmospheric System in Association with the Northern Summer SST Changes
}

\author{
Jau-Ming Chen ${ }^{1, *}$ and Mong-Ming Lu ${ }^{1}$ \\ (Manuscript received 21 September 1998, in final form 5 June 2000)
}

\begin{abstract}
The purpose of this study is to analyze the dynamic and hydrological characteristics of the interannual variability of the northern summer (JuneAugust) ocean-atmosphere system in the Asian-Pacific region. In this oceanatmosphere system, there are two types of interannual variability modes. As indicated by the sea surface temperature (SST) variability, the first type is related to the variations of the mature phase of the El Niño-Southern Oscillation (ENSO) events. Its temporal variability is characterized by alternations between the maximum phases of the EI Niño and La Niña events. Its spatial structure is characterized by an elongated positive (negative) SST anomaly over the tropical eastern Pacific during the El Niño (La Niña) event. The second type is related to SST variability between the developing and decaying stages of the ENSO events. This mode is characterized by warm (cold) SST anomalies in the tropical central and eastern Pacific during the developing stage of the El Niño (La Niña) event, and warm (cold) SST anomalies near the Peruvian coast during the decaying stage.

In accordance with these two types of interannual SST variability, tropical convection and the upward branches of Walker circulation are found enhanced (suppressed) in association with the warm (cold) SST anomalies. The centers of tropical convection anomaly coincide well spatially with the centers of major vertical motion branches and SST anomalies in the tropical western Pacific. The centers are to the west of the centers of vertical motion branches and SST anomalies in the central and eastern Pacific.

In the atmospheric system, the lower-tropospheric circulation anomalies corresponding to the first interannual mode contain spatial structures largely opposite to the climatological mean circulation. These anomalies represent the weaker Asian low and Pacific subtropical high during the El Niño event, which lead tó weaker tropical monsoon westerlies and Pacific trade winds. The lower-tropospheric circulation anomalies corresponding to the second interannual mode are characterized by an anomalous low
\end{abstract}

\footnotetext{
${ }^{1}$ Research and Development Center, Central Weather Bureau, Taipei, Taiwan

${ }^{*}$ Corresponding author address: Dr. Jau-Ming Chen, Research and Development Center, Central, Weather Bureau, 64 Kung-Yuan Rd. Taipei, Taiwan, 100; E-mail: cjming@rdc.cwb.gov.tw
} 
centered in the western Pacific during the developing stage of the El Niño event. This anomalous low later develops into an anomalous high during the decaying stage. For both types of interannual mode, water vapor convergence toward the convection-enhanced region is observed. Such convergence results in an increase in atmospheric water vapor and thus maintains the positive precipitation anomalies. Enhanced precipitation and tropical convection are found embedded in the lower-tropospheric anomalous lows and accompanied by intensified transient activity. Water vapor divergence, negative precipitation anomaly, and weaker transient activity are found for the convection-suppressed region.

(Key Words: Interannual variation, ENSO, Tropical convection, Circulation, Precipitation, Transient activity)

\section{INTRODUCTION}

In the Asian-Pacific region, the most significant interannual variability in the oceanic system is the EI Niño-La Niña oscillation. In the El Niño phase, the sea surface temperature (SST) exhibits strong warm anomalies along the equatorial eastern Pacific and minor cold anomalies over the tropical western Pacific (Rasmusson and Carpenter 1982). These SST anomalies reverse their polarity in the La Niña phase. The warm/cold SST anomalies are accompanied with enhanced/suppressed tropical cumulus convection that further couples with the upward/downward branch of the tropical Walker circulation anomaly (e.g., Deser and Wallace 1990; Wang 1992). The Walker circulation has been described as being composed of the planetary-scale divergent circulation (also called irrotational circulation) (Krishnamurti 1971). Moreover, the divergent circulation is generally paired with the rotational circulation to depict the atmospheric circulation system (Sardeshmukh and Hoskins 1988; Chen and Chen 1990). These dynamic relationships imply that variability of the Walker circulation is connected with variability of the planetary-scale atmospheric circulation. They also suggest that SST variability can affect the atmospheric variability through the coupling of the tropical convection and Walker circulation.

The interannual SST anomalies associated with the El Niño or La Niña events generally reach their maximum intensity in the northern winter (December-February). Therefore, the relationship between interannual SST anomalies and atmospheric variability in the northern winter has been extensively studied and is better understood than in the other seasons (e.g., Horel and Wallace 1981; Blackmon et al. 1983; Graham et al. 1994). Recently, the international meteorological community began to stress the importance of the dynamic relationship between the interannual SST variations and northern summer (June-August) atmospheric systems, in particular the Asian monsoon (CLIVAR 1995). Ju and Slingo (1995) and Li and Yanai (1996) pointed out that during the El Niño phases, the Asian summer monsoon tended to have a delayed onset and lower monsoon rainfall. These features were accompanied by a broader-scale reduction in the intensity of monsoon circulation and water vapor convergence 
toward the Asian monsoon region (Yang and Lau 1998). These results suggest that the El Niño-related Pacific SST anomalies may be systematically linked with the interannual variability of the northern summer atmospheric system in the Asian-Pacific region through the variability of monsoon precipitation and circulation.

The above reviews reveal that past studies dealing with the interannual variability of the northern summer ocean-atmosphere system paid particular attention to the relationships between the Pacific SSTs, monsoon precipitation, and atmospheric circulation. In addition to these aspects, the interannual characteristics of other atmospheric processes require further investigation. For example, the precipitation anomaly was found important in the connection between Asian monsoon circulation and Pacific SSTs. Nevertheless, how the interannual variability of the precipitation was maintained is still not clear. To answer this question, we need to examine the interannual variability of the hydrological processes. In another aspect, the synoptic-scale transient activity was found to vary coherently with the planetary-scale atmospheric circulation anomalies in the northern winter (Lau 1988; Matthews and Kiladis 1999). However, the dynamic relationships between the interannual variations of transient activity and atmospheric circulation in the northern summer still remain unclear. Further studies are surely needed to understand the interannual variability of the northern summer ocean-atmosphere system.

The purpose of this study is to analyze the dynamic and hydrological characteristics of the interannual variability of the northern summer ocean-atmospheric system. In this study, we analyze the interannual characteristics of the following oceanic and atmospheric fields: SST, tropical cumulus convection inferred from Outgoing Longwave Radiation (OLR), Walker circulation, atmospheric circulation, transient activity, and hydrological processes. Each of these fields is selected for a particular reason. SST anomalies are employed as the reference to define the phases of interannual variability. The tropical cumulus convection and Walker circulation are used to portray the response of the atmosphere to the underlying SST forcing. Atmospheric circulation and transient activity are employed to illustrate the response of the atmospheric flow system to the summer SST changes. Hydrological processes are analyzed in order to determine how moisture fields maintain the interannual precipitation anomaly. By incorporating the above analyses, we hope to gain a more comprehensive understanding of the dynamic characteristics of the interannual variability of the northern summer ocean-atmosphere system.

The outline of this study is as follows. Data used to porray the northern summer interannual modes are described in Section 2. The climatology and interannual variability of SSTs are presented in Section 3. Anomalies of the tropical cumulus convection and Walker circulation associated with the summer SST changes are discussed in Section 4. In Sections 5,6, and 7, climatologies and interannual variations of atmospheric circulation, transient activity, and hydrological processes, respectively, are analyzed. Concluding remarks are in Section 8.

\section{DATA}

The following monthly-mean data for the period 1979-95 are analyzed in this study: (a) 
SST and OLR compiled by the Climate Prediction Center of the National Centers for Environmental Prediction (NCEP); (b) moisture and upper air wind fields of the NCEP/NCAR (National Center for Atmospheric Research) reanalysis data (Kalney et al. 1996); and (c) precipitation estimates compiled from rain gauge measurements and satellite data (Xie and Arkin 1996). SST data are in a $2^{\circ} \times 2^{\circ}$ grid and the other data are in a $2.5^{\circ} \times 2.5^{\circ}$ grid. In all analyses, the northern summer (June-August) mean fields are used. In previous studies, it was found that an interdecadal trend has existed in the ocean-atmosphere system during the past four decades (e. g., Deser and Blackmon 1993; Jones 1994). In order to examine the interannual variability phenomenon specifically, the interdecadal trend embedded in the 1979-95 northern summer mean fields is removed from the analyses using a least-square-fit method.

\section{CLIMATOLOGY AND INTERANNUAL VARIABILITY OF THE NORTHERN SUMMER SSTS}

In order to make a better interpretation of the dynamic characteristics of the interannual SST anomaly, the spatial pattern of the interannual SST anomaly is compared with the climatological SST pattern. The SST climatology of the 1979-95 northern summer over the AsianPacific region is shown in Fig. 1a. This SST climatology displays a major warm center (e.g., above $28^{\circ} \mathrm{C}$ ) over the tropics and northern subtropics of the western Pacific. Warm SSTs extend westward to the oceans surrounding the Indian subcontinent and eastward to the central Pacific. Over the eastern Pacific, a belt of warm SSTs spreads just north of the equator in parallel with the overlying Intertropical Convergence Zone (ITCZ). To the south of this warm SST belt, tropical SSTs decrease significantly from the date line toward the east end of the Pacific. This SST distribution forms a cold tongue over the tropical eastern Pacific. In the tropics, the northern summer SST climatology is warmer in the western than in the eastern Pacific.

In the analyses of the interannual characteristics of the northem summer SSTs, we first evaluate the intensity of the interannual variability which is inferred from the root-mean-square (RMS) value of SST anomalies ( $\Delta$ SST). The $\Delta$ denotes a deviation from the 1979-95 summer mean. The RMS distribution of the 1979-95 northern summer SST anomalies over the Asian-Pacific region is displayed in Fig. 1b. Its salient feature is a maximum center over the eastern-Pacific Niño-3 region (i.e., $150^{\circ} \mathrm{W}-90^{\circ} \mathrm{W}, 5^{\circ} \mathrm{S}-5^{\circ} \mathrm{N}$ ). Since the SST value averaged over the Niño-3 region is used as an index to depict the evolution of the El Niño-Southern Oscillation (ENSO) phenomenon, the existence of the SST RMS maximum center over the Niño-3 region implies the dominance of ENSO-related SST variability in the interannual variation of the northern summer SSTs. In contrast to the noticeable RMS pattern over the eastern Pacific, the RMS pattern over the western Pacific and Indian Oceans is much weaker and not organized. Apparently, the major center of action for the interannual variability of the northern summer SSTs resides over the tropical eastern Pacific.

The primary temporal characteristics of the northern summer SST changes may be illustrated by the time series of $\triangle$ SST anomalies averaged from the maximum RMS center, i.e., the Niño-3 region. This $\Delta$ SST time series (Fig. 1c) has a standard deviation of $0.804^{\circ} \mathrm{C}$. Using 

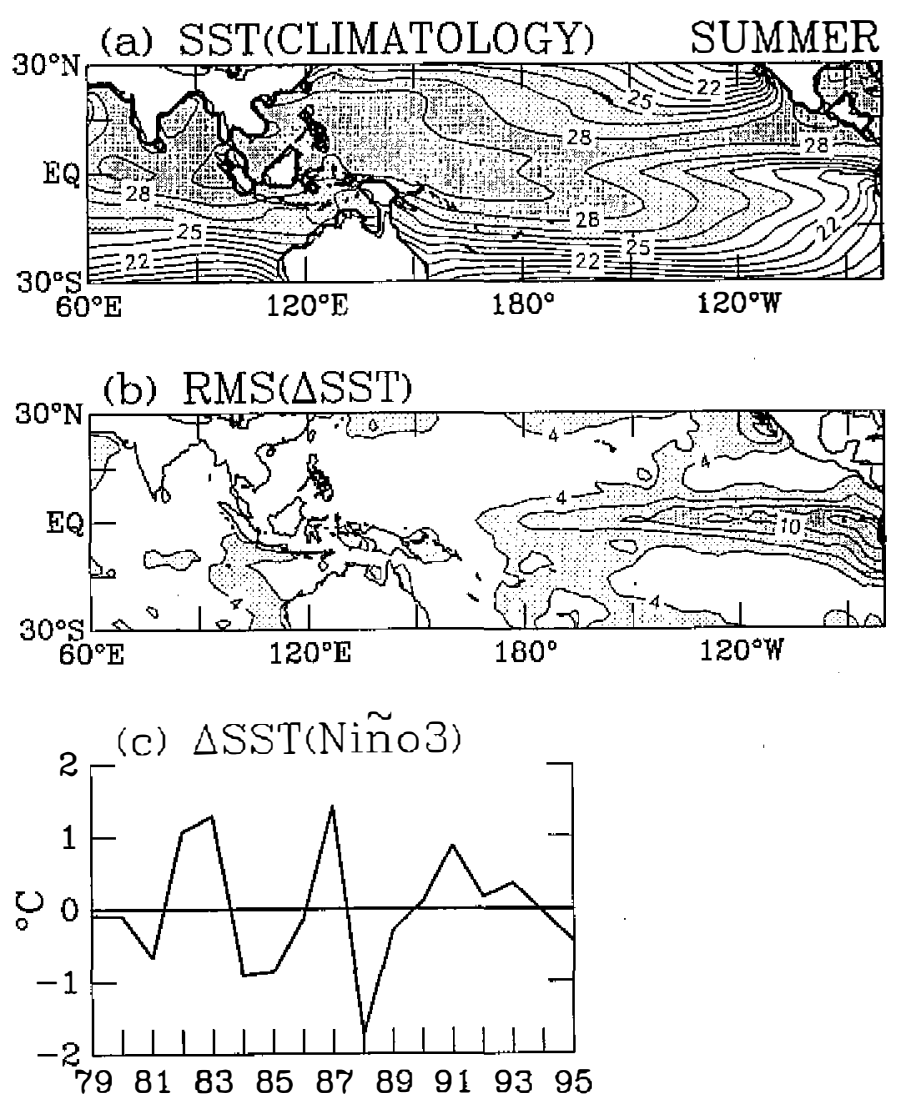

Fig. 1. (a) The 1979-95 climatology of the northem summer (June-August) SSTs over the Asian-Pacific region, (b) root mean square (RMS) pattern of the northem summer SST anomalies deviated from the 1979-95 climatology, i.e., RMS $(\Delta \mathrm{SST})$, and (c) the time series of $\triangle \mathrm{SST}$ averaged from the Niño-3 region $\left(150^{\circ} \mathrm{W}-90^{\circ} \mathrm{W}, 5^{\circ} \mathrm{S}-5^{\circ} \mathrm{N}\right)$. In (a), contour intervals are $1^{\circ} \mathrm{C}$. SST values between $25^{\circ} \mathrm{C}$ and $28^{\circ} \mathrm{C}$ are lightly shaded and those larger than $28^{\circ} \mathrm{C}$ are heavily shaded. In (b), contour intervals are $0.2^{\circ} \mathrm{C}$. RMS values between $0.4^{\circ} \mathrm{C}$ and $0.8^{\circ} \mathrm{C}$ are lightly shaded and those larger than $0.8^{\circ} \mathrm{C}$ are heavily shaded.

this value as a threshold, we define the summers of $82,83,87$ and 91 as relatively warmer and those of 84,85 and 88 as relatively colder. It should be interesting to discuss the phase relationship between these relatively warm/cold summers and the El Niño/La Niña events. As defined by Trenberth (1997), the El Niño (La Niña) phenomenon occurs when the SST anomaly over the Niño-3 region is warmer (colder) than a 0.5 standard deviation of its own monthlymean time series for the period 1951-97. According to this definition, the four warmer summers in 82,83,87, and 91 overlap the periods of major El Niño events in 82/4-83/7, 86/8-88/2, and $91 / 3-92 / 7$. The three colder summers in 84,85 , and 88 are around the major La Niña events 
in the periods $84 / 9-85 / 6$ and $88 / 5-89 / 6$. The above phase relationships demonstrate clearly that there is an ENSO signature on the interannual variability of the northern summer SSTs.

In order to examine the spatial and temporal characteristics of the northem summer SST changes simultaneously, SST anomalies are subjected to the Empirical Orthogonal Function (EOF) analysis. The first two EOF eigenmodes of the interannual SST anomalies over the tropical Asian-Pacific region are displayed in Fig. 2. The total interannual SST variance accounted for by the first and second eigenmodes is $46 \%$ and $14 \%$, respectively. These percentages are hereafter displayed in the upper-right corner of eigencoefficient plots, as shown in Figs. $2 \mathrm{a}$ and $2 \mathrm{~b}$.
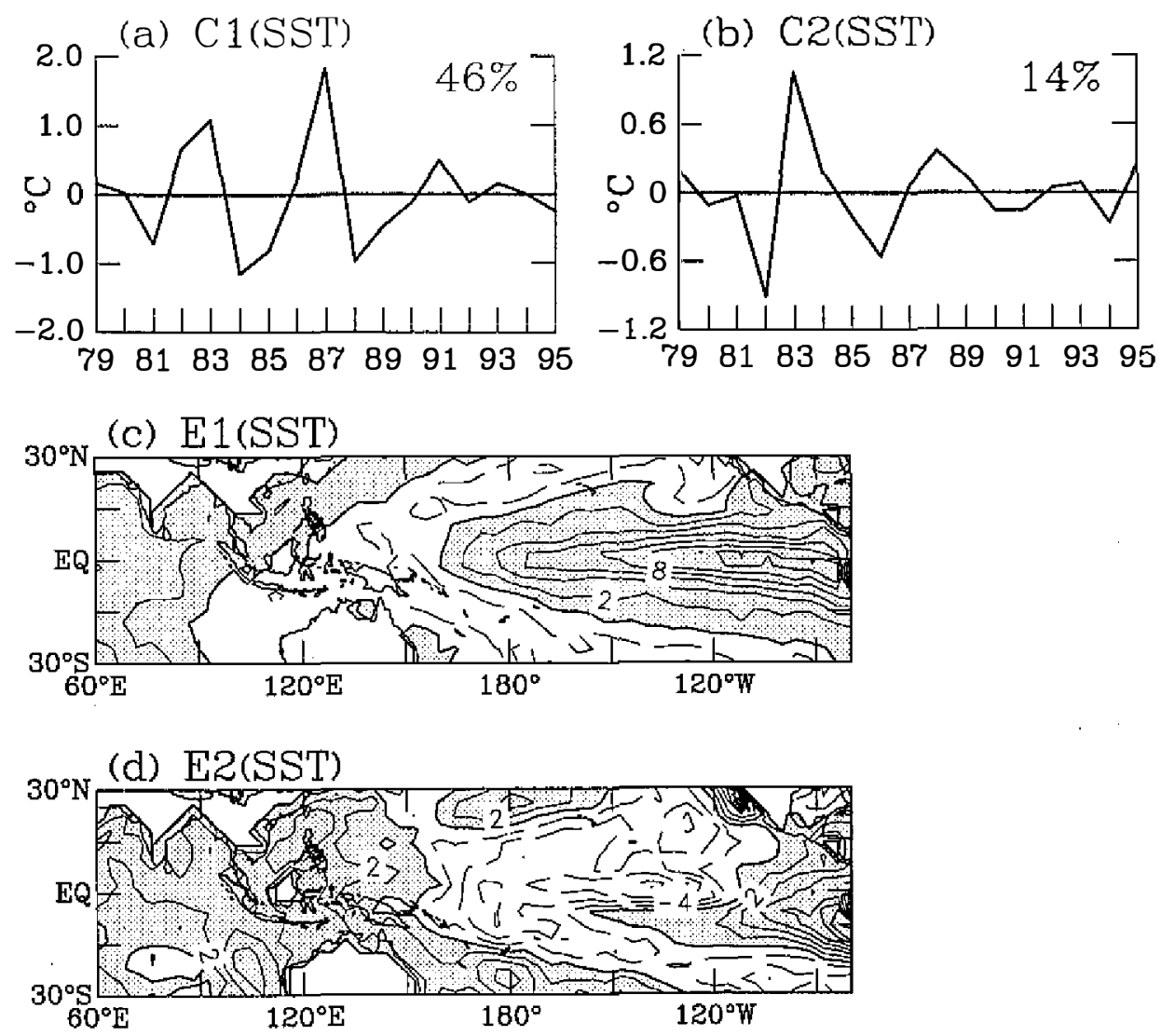

Fig. 2. The first two eigenmodes of the northern summer interannual SST anomalies over the Asian-Pacific region: (a) the first eigencoefficient (C1), (b) the second eigencoefficient (C2), (c) the first eigenvector (E1), and (d) the second eigenvector (E2). The total interannual SST variances accounted for by the first and second eigenmodes are $46 \%$ and $14 \%$, respectively. These percentages are hereafter shown in the upper-right corner of the eigencoefficient plots. In (c) and (d), contours intervals are 0.2 and positive values are shaded. 
In the first SST eigenmode, the first eigenvector (E1; Fig. 2c) shows a spatial structure resembling the typical ENSO pattern. This is a major positive center stretching from the eastern-Pacific Niño-3 region westward to the equatorial central Pacific, and it is surrounded by horseshoe-shaped negative anomalies with weaker magnitudes over the tropical western $\mathrm{Pa}$ cific and the subtropical eastern Pacific. With such a typical ENSO pattern, the E1(SST) pattern resembles the SST RMS pattern in Fig. Ib. The E1(SST) also shows that, during its positive phase, the SST anomaly is warmer in the eastern Pacific and colder in the western Pacific. Such a longitudinal distribution in the tropical Pacific is out of phase with SST climatology (Fig. 1a). This result indicates that the first SST mode tends to weaken (enhance) the east-west contrast of the northern summer tropical Pacific SSTs during its positive (negative) phase.

The temporal variation of the first SST eigenmode, as illustrated by the first eigencoefficient (C1; Fig. 2a), seems to vary coherently with the Niño-3 $\Delta$ SST time series in Fig. 1c. C1(SST) contains maximum phases in summers of 82,83,87 and 91 and minimum phases in those of 84 , 85 and 88 . These maximum (minimum) phases correspond to the relatively warm (cold) phases of the Niño-3 $\Delta$ SST time series. The temporal coherence between C1(SST) and the Niño-3 $\Delta$ SST time series is statistically substantiated by a 0.92 correlation coefficient. According to these temporal features, we conclude that the dominant interannual variability in C1(SST) is associated with the oscillations between the major El Niño and La Niña events (or the mature phases of ENSO events). Based upon the spatial and temporal features depicted by the E1 (SST) and C1(SST), we interpret the first SST eigenmode as an ENSO-related mode which reflects the interannual SST variability caused by the alternation between the major El Niño and La Niña events. This SST mode also reveals that the intensity of tropical Pacific SSTs is weakened (enhanced) during the mature phase of the El Niño (La Niña) event.

The second SST eigenmode has only about one third the intensity of the first, as inferred from the percentage of variance. The second eigenvector (E2; Fig. 2d) features a major negative center over the tropical central Pacific, and two major positive centers over the South China Sea-western Pacific region and the eastern Pacific adjacent to the Peruvian coast. The amplitudes of these three centers are comparable. E2(SST) thus shows a three-center pattern which differs from the single-dominant-center pattern of E1(SST).

The temporal variation of the second eigencoefficient (C2; Fig. 2b) exhibits large negative phases in the summers of 82 and 86 , and large positive phases in the summers of 83 and 88. These summers happen to be in the periods around the major El Niño events. The summers of 82 and 83 are in the developing and decaying stages, respectively, of the 82/4-83/7 El Niño event. Similarly, the summers of 86 and 88 are in the prior and posterior periods, respectively, of the 86/8-88/2 El Niño event. These temporal relationships suggest that the major negative (positive) C2(SST) phase corresponds to the developing (decaying) stage of the major El Niño event. This type of phase relationship also applies to another major El Niño event during 91/3$92 / 7$. C2(SST) switches from a negative phase in the summer of 91 into a positive phase in that of 92 , but with a much weaker change in amplitude. On the other hand, a reversed phase relationship is found for the La Niña events. During the major La Niña events in the periods of $84 / 9-85 / 6$ and $88 / 5-89 / 6, \mathrm{C} 2$ (SST) fluctuates from positive phases in the developing stages during the summers of 84 and 88 into relatively negative phases in the decaying stages during those of 85 and 89. According to the spatial and temporal structures of the second SST mode, 
one can infer that warm SST anomalies are located in the central Pacific during the developing phase of the El Niño event (negative E2, negative C2). Warm SST anomalies later move to the eastern Pacific during the decaying phase (positive E2, positive C2). Based upon the above analyses, we conclude that the second SST mode represents the interannual SST variability induced by changes in the summer SST anomalies between the developing and decaying stages of ENSO events.

Our EOF analyses reveal the existence of significant ENSO signatures in the interannual variability of the northern summer SSTs. The dominant interannual variability of the first SST mode is related to variability of the tropical Pacific SSTs between major El Niño and La Niña events. In fact, this kind of SST variability also dominates the interannual variability of the northern winter SSTs and has already attracted research attention to study its impact on the northern winter atmospheric system (e.g., Lau and Nath 1994; Lau et al. 1998). On the other hand, the second SST mode is often ignored because of its weak intensity. However, our analysis suggests that this SST mode is important because it represents the interannual SST variability resulting from the variability of SSTs between the developing and decaying stages of ENSO events. Therefore, it is of interest to study the impacts of the first two SST modes on the northern-summer atmosphere.

\section{INTERANNUAL VARIABILITY OF WALKER CIRCULATION AND OLR}

In this section, we analyze anomalies of the Walker circulation and tropical cumulus convection in order to examine the impacts of the interannual SST mode on the vertical motion of the atmosphere. The Walker circulation anomalies associated with the first and second SST modes are shown in Figs. 3a and 3b, respectively. To construct these anomalies, we first compute two types of composites based upon the negative phases or positive phases of each SST eigencoefficient. The difference between these two composites (positive phase - negative phase) is considered as the typical response of the Walker circulation to the positive phase of the interannual SST mode. The Walker circulation is expressed by a mass flux function $\Psi_{m}=\int_{p_{1}}^{{ }^{p_{o}}} u_{d} d p$ (Newell et al. 1974), where $p_{1}=100 \mathrm{mb}, p_{0}=1000 \mathrm{mb}, u_{d}$ is the zonal divergent wind, and $\mathrm{p}$ is the pressure. A positive (negative) $\Psi_{\mathrm{m}}$ cell indicates a two-dimensional counterclockwise (clockwise) motion. $\Psi_{\mathrm{m}}$ anomalies associated with the first/second SST mode are extracted from the longitude-height section at the equator $10^{\circ} \mathrm{S}$ in order to portray vertical motions above the one-center/three-center pattern in the first/second SST eigenvector. As shown in Fig. $3 \mathrm{a}, \Psi_{\mathrm{m}}$ anomalies related to the first SST mode contain one dominant positive cell above the tropical Pacific and one negative cell to the west of $130^{\circ} \mathrm{E}$. These two $\Psi_{\mathrm{m}}$ cells suggest there are major updraft branches at around $150^{\circ} \mathrm{W}$ and $80^{\circ} \mathrm{E}$ with a major downdraft branch at around $130^{\circ} \mathrm{E}$. A comparison between the (m anomaly and E1 (SST) (Fig. 2c) reveals that the updraft branches at around $150^{\circ} \mathrm{W}$ and $80^{\circ} \mathrm{E}$ are above the warm SST anomalies over the ropical eastern Pacific and ropical Indian Ocean, respectively. The downdraft section around $130^{\circ}$ E matches the underlying cold SST anomaly over the ropical western Pacific. For the $\Psi_{m}$ anomalies associated with the second SST mode (Fig. 3b), its spatial pattern includes a dominant negative cell to the west of $170^{\circ} \mathrm{E}$ and a positive cell to the 

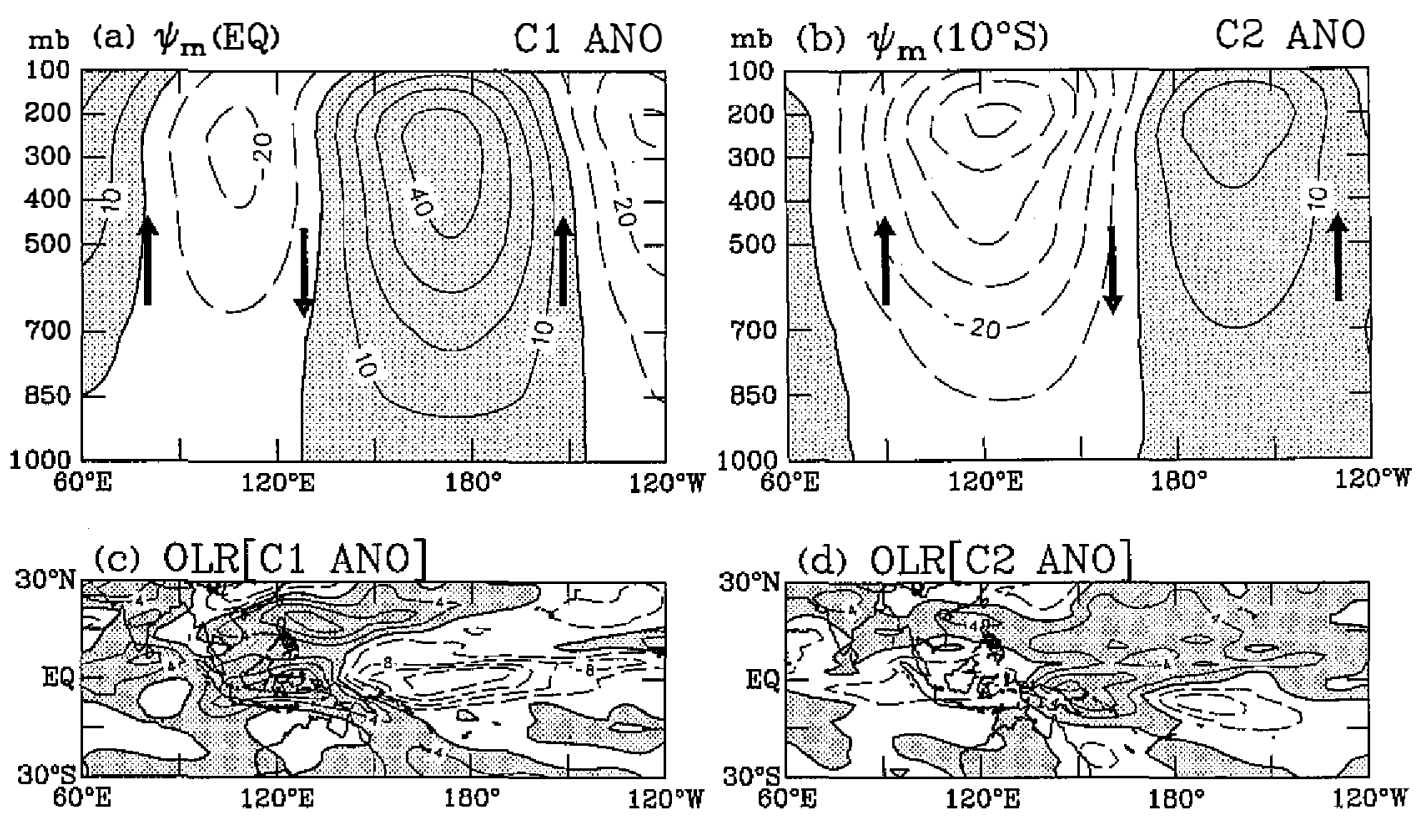

Fig. 3. The interannual anomalies of (a)/(b) Walker circulation and (c)/(d) OLR associated with the first/second SST eigenmode. The Walker circulation is represented by a mass flux function $\left(\Psi_{m}\right)$. Details on computing these anomalies are given in the text. Contour intervals are $10 \mathrm{~ms}^{-1} \mathrm{mb}$ in (a) and (b), and $4 \mathrm{Wm}^{-2}$ in (c) and (d). In all plots, positive values are shaded.

east. In association with these two $\Psi_{\mathrm{m}}$ cells, the updraft sections are located at around $120^{\circ} \mathrm{W}$ and $90^{\circ} \mathrm{E}$ and match the tropical warm E2(SST) anomalies (see Fig. 2d) over the eastern Pacific and Indian Ocean, respectively. Meanwhile, the downdraft section is located at around $160^{\circ} \mathrm{E}$ and corresponds to an underlying cold E2(SST) anomaly in the tropical central Pacific. The above spatial relationship describes that the major updraft (downdraft) branches of the Walker circulation anomaly match the anomalous warm (cold) SSTs.

The interannual variability of tropical cumulus convection associated with the interannual SST modes is inferred from OLR anomalies constructed in the same manner as ( $\mathrm{m}$ anomalies. OLR anomalies corresponding to the first SST mode (Fig. 3c) feature two tropical centers. The positive center over the tropical western Pacific northwest of Australia indicates that the convection is suppressed over there. On the contrary, the convection is enhanced over the tropical central Pacific, as indicated by a negative OLR center. In Fig. 3d, the OLR anomaly related to the second SST mode displays three tropical regimes: suppressed convection (positive anomaly) over the western Pacific northeast of Australia, and intensified convection (negative anomaly) over the Indian Ocean-South China Sea region and the central Pacific east of the date line.

We also compare the spatial patterns of OLR and $\Psi_{\mathrm{m}}$ anomalies and find some interesting results. In both modes, the centers of positive OLR anomalies over the tropical western 
Pacific are located within the major downdraft sections of $\Psi_{\mathrm{m}}$ anomalies, such as the sections at around $130^{\circ} \mathrm{E}$ in Fig. $3 \mathrm{a}$ and $160^{\circ} \mathrm{E}$ in Fig. 3b. However, the centers of negative OLR anomalies over the tropical central Pacific in the vicinity of the date line are located westward about $30^{\circ}-50^{\circ}$ longitude from the major updraft sections of $\Psi_{\mathrm{m}}$ anomalies, such as the sections at around $150^{\circ} \mathrm{W}$ in Fig. $3 \mathrm{a}$ and $120^{\circ} \mathrm{W}$ in Fig. 3b. These spatial relationships indicate that the centers of OLR anomalies and tropical vertical motion are more consistent in geographical distribution in the western Pacific than in the central and eastern Pacific. The above results may be attributed to the longitudinal dependence of the air-sea interaction processes (Wang 1992). In the tropical westem Pacific, the atmospheric stability is weak. Vertical motion and convection are both sensitive to changes in extermal boundary condition such as the underlying SSTs. This characteristic leads to a spatial consistency among the anomalous centers of these fields. On the other hand, the tropical atmosphere over the central and eastern Pacific becomes more stable because it is underneath the subsidence of the climatological Walker circulation. In this region, the pressure gradient force associated with the SST gradient induces the boundary-layer convergence that determines atmospheric heating. The OLR center tends to match the locations of atmospheric heating and the zonal SST gradient, rather than the center of SST anomalies. Therefore, the anomalous OLR centers over the central and eastern Pacific are located westward from the anomalous SST center and the major branch of the Walker circulation anomaly.

\section{CLIMATOLOGY AND INTERANNUAL VARIABILITY OF ATMOSPHERIC CIRCULATION}

In the next two sections, the impacts of the interannual SST modes on the horizontal motion of the atmosphere are examined from the interannual variability of the planetary-scale atmospheric circulation and synoptic-scale transient activity. The atmospheric circulation can be separated into the divergent circulation and rotational circulation (e.g., Holton 1992) that are often depicted by the velocity potential $\left(\chi=\nabla^{-2}[\nabla \bullet V]\right)$ and streamfunction $\left(\Psi=\nabla^{-2} \zeta\right)$, respectively. The eddy components of the velocity potential $\left(\chi_{\mathrm{E}}\right)$ and streamfunction $\left(\Psi_{\mathrm{E}}\right)$ at $850 \mathrm{mb}$ averaged from the 1979-95 northern summers are used to illustrate the climatology of atmospheric circulation. In Fig. $4 \mathrm{a}$, the climatological $\chi_{\mathrm{E}}(850 \mathrm{mb})$ field shows a convergence of atmospheric flows (positive pattern) toward the Asian-western Pacific region with a center around the Philippines. In contrast, atmospheric flows are divergent (negative pattern) out of the eastern Pacific. A comparison between the $\chi_{\mathrm{E}}(850 \mathrm{mb}$ ) climatology and SST climatology (Fig. 1a) reveals that the western-Pacific convergence center overlaps the warm SST center, while the eastern-Pacific divergence sector overlaps the SST cold tongue. This result indicates that the low-latitude $\chi_{\mathrm{E}}(850 \mathrm{mb})$ pattern is sensitive to the thermal structure of the underlying sea surface condition. Thus, the $\chi_{E}(850 \mathrm{mb})$ field is often used to illustrate the distribution of the atmospheric heat source (e.g., convergence sector) and heat sink (e.g., divergence sector) in accordance with the external heat conditions.

In the rotational circulation, the salient feature of the climatological $\Psi_{E}(850 \mathrm{mb})$ field (Fig. 4b) is two east-west pairs of lows and highs. In the northern hemisphere (NH), $\Psi_{E}(850$ 

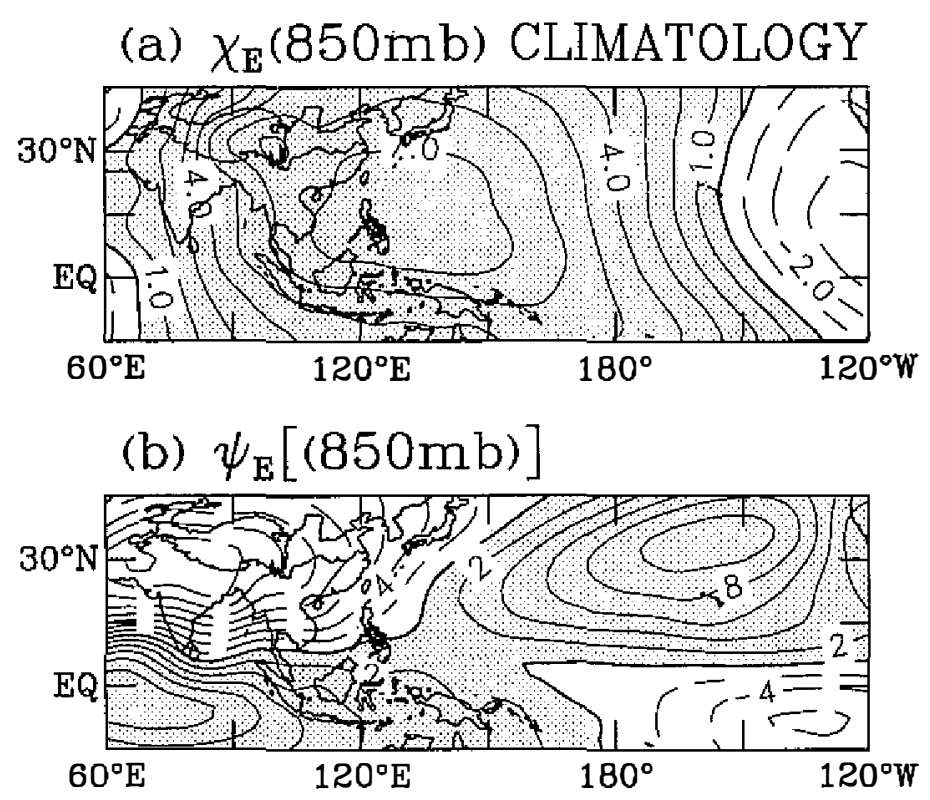

Fig. 4. The 1979-95 northern summer climatology of the planetary-scale atmospheric circulation. The divergent and rotational components of the atmospheric circulation are represented by the eddy components of (a) velocity potential $\left(\chi_{\mathrm{E}}\right)$ and $(\mathrm{b})$ streamfunction $\left(\Psi_{\mathrm{E}}\right)$ at $850 \mathrm{mb}$, respectively. Contour intervals are $10^{6} \mathrm{~m}^{2} \mathrm{~s}^{-1}$ in (a) and $2 \times 10^{6} \mathrm{~m}^{2} \mathrm{~s}^{-1}$ in (b). All positive values are shaded.

$\mathrm{mb}$ ) is dominated by a monsoon low over the Asian continent and a subtropical high over the North Pacific. This low-high pair is accompanied by another low-high pair in the southern hemisphere (SH), but with opposite polarity. The above $\Psi_{\mathrm{E}}(850 \mathrm{mb})$ patterns contain a unique phase relationship with the $\chi_{\mathrm{E}}(850 \mathrm{mb})$ patterns in Fig. $4 \mathrm{a}$. In each hemisphere, the east-west pair of low and high reside over two sides of the maximum $\chi_{E}(850 \mathrm{mb})$ convergence center around the Philippines. This result indicates that the maximum phase of $\chi_{E}(850 \mathrm{mb})$ (i.e., convergence center) more or less matches the node phase of $\Psi_{\mathrm{E}}(850 \mathrm{mb})$, where the zerocontour line is located. Their phase difference, about one quarter wavelength or 90 degrees, reveals the existence of a spatially quadrature relationship between the $\chi_{\mathrm{E}}(850 \mathrm{mb})$ and $\Psi_{\mathrm{E}}$ $(850 \mathrm{mb})$ fields. Since a quadrature relationship was found between the atmospheric waves and the idealized tropical heat source that excites these waves (Matsuno 1966; Gill 1980), the quadrature relationship is usually interpreted as existing between the heat source field (like $\chi_{\mathrm{E}}$ field) and its responding atmospheric wave fields (like $\Psi_{E}$ field).

The interannual variability of the planetary-scale atmospheric circulation is illus ated by the first two eigenmodes of $\chi_{E}(850 \mathrm{mb})$ and $\Psi_{E}(850 \mathrm{mb})$. As displayed in Figs. 5a and 5c, the time series of $\mathrm{C} 1\left[\chi_{\mathrm{E}}(850 \mathrm{mb})\right]$ and $\mathrm{C} 1\left[\Psi_{\mathrm{E}}(850 \mathrm{mb})\right]$ show relatively similar temporal phases. Their phases are also coherent with the $\mathrm{C} 2$ (SST) phases(Fig. 2b). For example, the particular features of C2(SST), i.e., phase changes from negative states in the summers of 82,86 and 91 

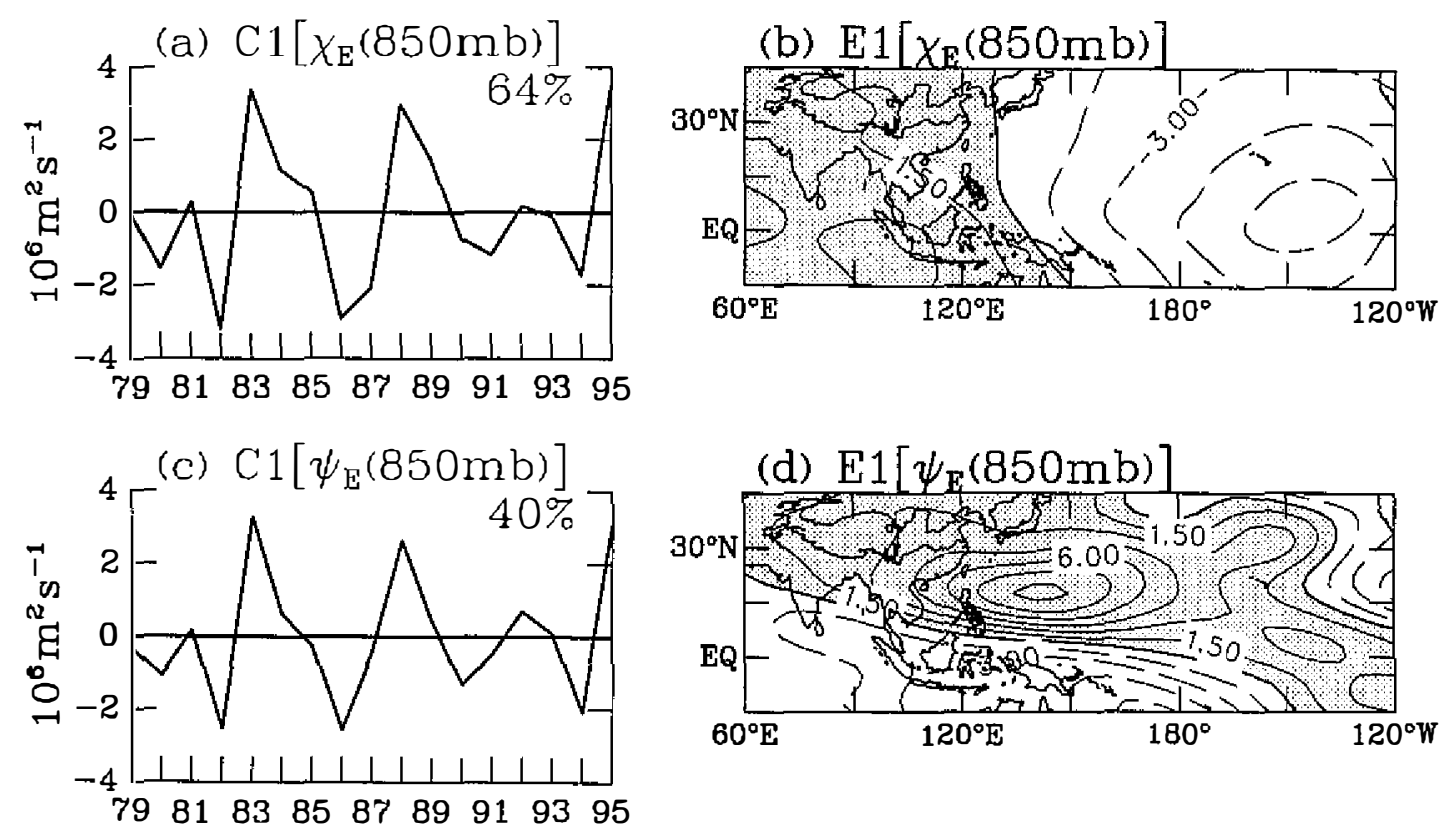

Fig. 5. The first interannual eigenmodes of $\chi_{\mathrm{E}}(850 \mathrm{mb})$ and $\Psi_{\mathrm{E}}(850 \mathrm{mb}):(\mathrm{a}) /$ (b) the first eigencoefficient/eigenvector of $\chi_{\mathrm{E}}(850 \mathrm{mb})$ and $(\mathrm{c}) /(\mathrm{d})$ the first eigencoefficienteigenvector of $\Psi_{\mathrm{E}}(850 \mathrm{mb})$. In (b) and (d), contour intervals are 0.15 and positive values are shaded.

into positive states in those of 83,88 and 92 , also exist in $\mathrm{C} 1\left[\chi_{\mathrm{E}}(850 \mathrm{mb})\right]$ and $\mathrm{C} 1\left[\Psi_{\mathrm{E}}(850\right.$ $\mathrm{mb})]$. The temporal coherence between $\mathrm{C} 1\left[\chi_{\mathrm{E}}(850 \mathrm{mb})\right] / \mathrm{C} 1\left[\Psi_{\mathrm{E}}(850 \mathrm{mb})\right]$ and $\mathrm{C} 2(\mathrm{SST})$ is justified by their $0.82 / 0.87$ correlation coefficient. These temporal relationships indicate that the first eigenmodes of $\chi_{E}(850 \mathrm{mb})$ and $\Psi_{E}(850 \mathrm{mb})$ are coherent with the second interannual SST mode.

In the spatial pattern, $\mathrm{E} 1\left[\chi_{\mathrm{E}}(850 \mathrm{mb})\right]$ (Fig. $\left.5 \mathrm{~b}\right)$ displays a divergent (negative) center over the central and eastern Pacific east of $150^{\circ} \mathrm{E}$ where a cold E2(SST) anomaly exists (see Fig. 2d). Over the Indian Ocean and South China Sea, the E1[ $\left.\chi_{E}(850 \mathrm{mb})\right]$ exhibits a convergent (positive) center which corresponds to a warm E2(SST) anomaly. It is clear that the convergent (divergent) center of the $\chi_{\mathrm{E}}(850 \mathrm{mb})$ field is connected with the warm (cold) SST anomaly. We also compare the spatial patterns of E1[ $\left.\chi_{E}(850 \mathrm{mb})\right]$ and $\mathrm{E} 1\left[\Psi_{\mathrm{E}}(850 \mathrm{mb})\right]$ (Fig. $5 \mathrm{~d})$. In the $\mathrm{NH}$, the $\mathrm{E} 1\left[\chi_{\mathrm{E}}(850 \mathrm{mb})\right]$ divergent center around $150^{\circ} \mathrm{W}$ is surrounded by a pair of $\mathrm{E} 1\left[\Psi_{\mathrm{E}}(850 \mathrm{mb})\right]$ anomalies with an anomalous high to the west and an anomalous low to the east. In the $\mathrm{SH}$, this divergent center is sandwiched by another east-west pair of $\Psi_{\mathrm{E}}$ anomalies with opposite polarity to the $\mathrm{NH} \Psi_{\mathrm{E}}$ anomalies. It is also clear that there is a spatially quadrature relationship between $\mathrm{E} 1\left[\chi_{\mathrm{E}}(850 \mathrm{mb})\right]$ and $\mathrm{E} 1\left[\Psi_{\mathrm{E}}(850 \mathrm{mb})\right]$. The above spatial relationships between E2(SST), E1 $\left.\chi_{\mathrm{E}}(850 \mathrm{mb})\right]$, and E1[ $\left.\Psi_{\mathrm{E}}(850 \mathrm{mb})\right]$ suggest that the interannual SST variability can exert impacts on the interannual variability of the atmospheric waves (inferred from E1 $\left[\Psi_{E}(850 \mathrm{mb})\right]$ ) by affecting the heat distribution of the summer atmosphere 
(inferred from $\left.\mathrm{E} 1\left[\chi_{\mathrm{E}}(850 \mathrm{mb})\right]\right)$.

The first $\chi_{\mathrm{E}}(850 \mathrm{mb})$ and $\Psi_{\mathrm{E}}(850 \mathrm{mb})$ eigenmodes are found to connect with the second SST mode which represents the interannual SST variability induced by contrasts between the developing and decaying stages of ENSO events. During the developing stage of the El Niño event (negative phase in eigencoefficient), the $\mathrm{E} 1\left[\Psi_{\mathrm{E}}(850 \mathrm{mb})\right]$ field shows an anomalous low (positive E1 [ $\left.\Psi_{\mathrm{E}}(850 \mathrm{mb})\right]$ pattern) over the western Pacific, which results in anomalous westerlies in the tropical western Pacific. The occurrence of anomalous tropical westerlies over the westem Pacific proceeding the mature El Niño phase has been observed in several studies and referred to as westerly wind bursts (e.g., Keen 1982; Nitta and Motoki 1987; Yamagata and Masumoto 1989). During the decaying stage of the El Niño event (positive phase in eigencoefficient), an anomalous high (positive $\mathrm{E} 1\left[\Psi_{\mathrm{E}}(850 \mathrm{mb})\right]$ pattern) and its associated tropical easterlies exist in the western Pacific. These anomalous tropical easterlies confine the warm sea surface water to the western Pacific, which guides the ocean condition back to the normal phase or even into the La Niña phase.

In the second atmospheric circulation modes, the temporal phases of $\mathrm{C} 2\left[\chi_{\mathrm{E}}(850 \mathrm{mb})\right]$ (Fig. 6a) and $\mathrm{C} 2\left[\Psi_{\mathrm{E}}(850 \mathrm{mb})\right]$ (Fig. 6c) are noticed by positive peaks over the summers of 82 , 83 and 87 in association with the 82-83 and 86-87 El Niño events, and negative peaks over the summers of 84 and 85 in relation to the $84-85 \mathrm{La}$ Niña event. These phase features are similar to those shown in the C1(SST). The correlation coefficient between C1[SST] and C2[ $\chi_{\mathrm{E}}(850$ $\mathrm{mb})]$ is 0.77 , and 0.83 between $\mathrm{C} 1[\mathrm{SST}]$ and $\mathrm{C} 2\left[\Psi_{\mathrm{E}}(850 \mathrm{mb})\right]$. These coefficients suggest that the second atmospheric circulation modes are connected to the first SST mode.
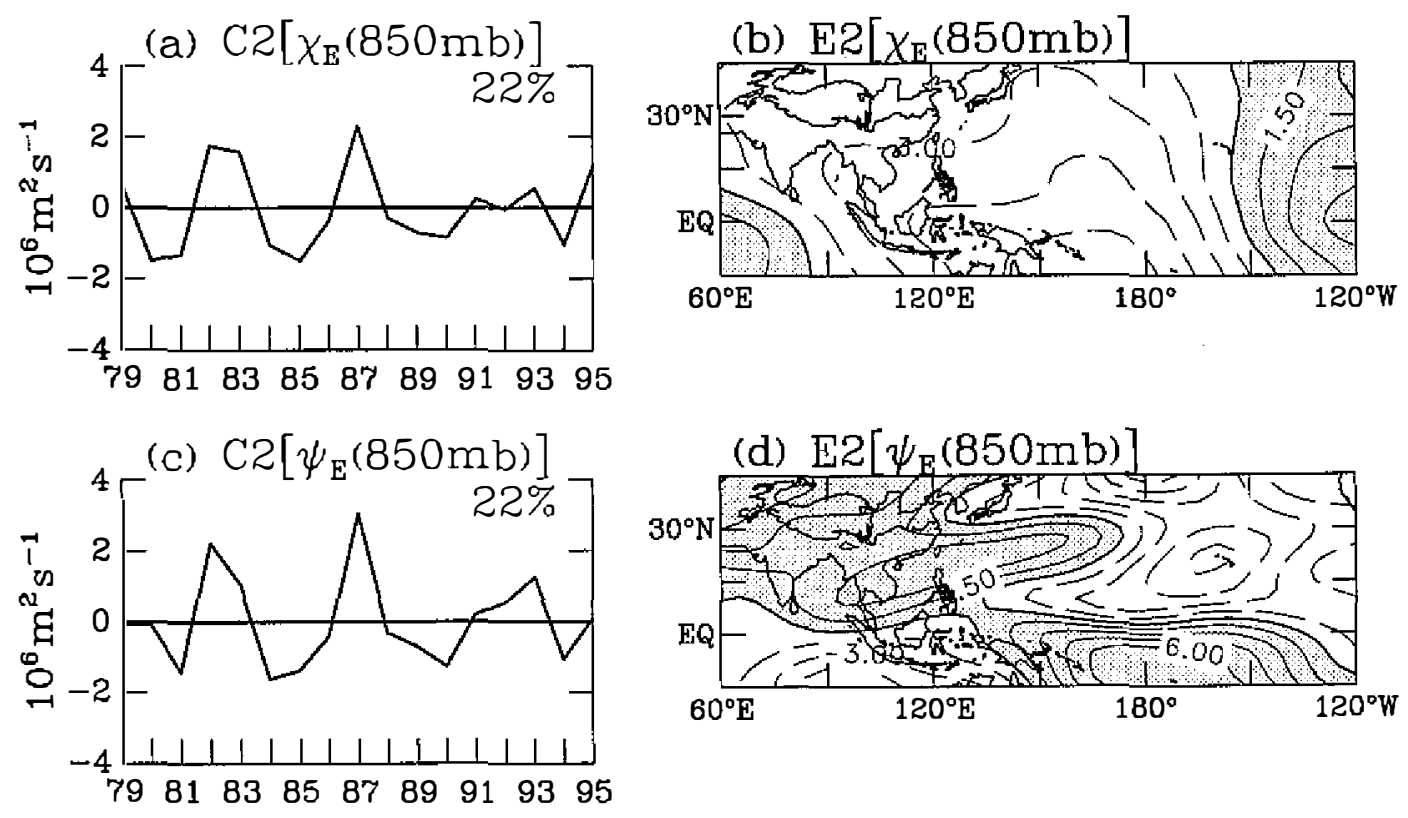

Fig. 6. As in Fig. 5, except for the second eigenmodes of $\chi_{\mathrm{E}}(850 \mathrm{mb})(\mathrm{a}-\mathrm{b})$ and $\Psi_{\mathrm{E}}(850 \mathrm{mb})(\mathrm{c}-\mathrm{d})$. 
In the spatial structure, the $\mathrm{E} 2\left[\chi_{\mathrm{E}}(850 \mathrm{mb})\right]$ pattern (Fig. $\left.6 \mathrm{~b}\right)$ shows an anomalous convergence region (positive anomaly) over the eastern Pacific with a center at around $120^{\circ} \mathrm{W}$, which corresponds to an underlying tropical warm E1(SST) anomaly (see Fig. 2c). Over the western and central Pacific, an anomalous divergence region (negative anomaly) is accompanied by the relatively cold E1(SST) anomaly. It appears that the convergence (divergence) region in E2 $\left.\chi_{\mathrm{E}}(850 \mathrm{mb})\right]$ tends to match the underlying warm (cold) E1(SST) anomaly. Such a spatial relationship is consistent with that found previously between E2(SST) and E1 [ $\Psi_{\mathrm{E}}$ $(850 \mathrm{mb})]$. We also examine the spatial relationship between E2[ $\left.\chi_{\mathrm{E}}(850 \mathrm{mb})\right]$ and E2 [ $\Psi_{\mathrm{E}}$ $(850 \mathrm{mb})]$. The central-Pacific divergent center to the west of the date line is sandwiched by an anomalous high stretching from the Asian continent into the western Pacific and an anomalous low over the North Pacific east of the date line. This pair of $\Psi_{\mathrm{E}}(850 \mathrm{mb})$ anomalies in the NH are accompanied by a pair of opposite-polarity $\Psi_{\mathrm{E}}$ anomalies in the $\mathrm{SH}$, which also sandwich the central-Pacific divergent center. These results indicate the existence of a spatially quadrature relationship between the $\mathrm{E} 2\left[\chi_{\mathrm{E}}(850 \mathrm{mb})\right]$ and $\mathrm{E} 2\left[\Psi_{\mathrm{E}}(850 \mathrm{mb})\right]$ fields.

The second $\Psi_{\mathrm{E}}(850 \mathrm{mb})$ mode exhibits some interesting features worthy of mention. The E2 $\left[\Psi_{E}(850 \mathrm{mb})\right]$ shows an anomalous high over the Asian-western Pacific region and an anomalous low over the North Pacific. Such an east-west distribution is largely opposite to $\Psi_{\mathrm{E}}(850 \mathrm{mb}$ ) climatology (Fig. 4b), which exhibits a low in Asia and a subtropical high in the North Pacific. In the SH, the east-west distribution of the circulation in the Pacific region also tends to be opposite between E2 $\left[\Psi_{\mathrm{E}}(850 \mathrm{mb})\right]$ and $\Psi_{\mathrm{E}}(850 \mathrm{mb})$ climatology. Note that the second $\Psi_{\mathrm{E}}(850 \mathrm{mb})$ mode is connected to the first SST mode. During the El Niño phase, this SST mode exhibits warm anomalies over the central-eastern Pacific and cold anomalies over the western Pacific. Such an east-west SST distribution is also opposite to the summer SST climatology. Since the tropical SST patterns are reversed between the E1(SST) and SST climatology, it is reasonable to find a reversal in the spatial pattern between the E2 [ $\Psi_{E}(850$ $\mathrm{mb})]$ and $\Psi_{\mathrm{E}}(850 \mathrm{mb})$ climatology. These results suggest that during the positive (negative) phase of the second $\Psi_{\mathrm{E}}(850 \mathrm{mb}$ ) mode which corresponds to the El Niño (La Niña) phase, the East-Asian summer monsoon circulation becomes weaker (stronger). Wang (2000) conducted composite analyses with the observational data and found that during the El Niño (La Niña) phase, the tropical central Pacific warming (cooling) and the weak (strong) East-Asian monsoon is connected by an anomalous high (low) over the western Pacific, which is clearly shown in the E2 $\left[\Psi_{\mathrm{E}}(850 \mathrm{mb})\right]$. Thus, Wang's finding regarding the dynamic relationship between the East-Asian monsoon and ENSO is supported by our diagnostic results for the second $\Psi_{\mathrm{E}}$ $(850 \mathrm{mb})$ mode and first SST mode.

\section{CIIMATOLOGY AND INTERANNUAL VARIABILITY OF TRANSIENT ACTIVITY}

Following the analysis of the planetary-scale atmospheric circulation, transient activity is analyzed in this section to illustrate the interannual changes of atmospheric flows on the synoptic scale. The ransient activity is computed following the statistical approach of Blackmon et al. (1977) and represented by the RMS value of the 2.5-7 day filtered $\Psi(850 \mathrm{mb})$ field for 
the period June-August. In this analysis, only the short-wave (wavenumbers 5-30) components of the $\Psi(850 \mathrm{mb})$ field are included. This RMS value is denoted as RMS( $\left.\Psi_{\mathrm{s}}^{\prime}\right)$. The climatology of RMS( $\Psi_{s}^{\prime}$ ) (Fig. 7) shows a maximum center stretching from the subtropical western Pacific off the coasts of the Asian continent southeastward to the equatorial central Pacific. The subtropical western Pacific is the location of the climatological $\chi_{E}(850 \mathrm{mb})$ convergence center (see Fig. 4a) where tropical cyclone activity is significant (McBride, 1995). Thus, the RMS ( $\left.\Psi_{\mathrm{s}}^{\prime}\right)$ center over the subtropical western Pacific is likely to reflect the active transient variability associated with tropical cyclone activity. The other maximum $\operatorname{RMS}\left(\Psi_{\mathrm{s}}^{\prime}\right)$ center over the equatorial central Pacific resides along the equatorial rim of the Pacific subtropical high (see Fig. 4b) where tropical disturbances, such as easterly waves and tropical cyclones, move westward following the prevailing tropical trade winds (e.g., Wallace and Chang 1969). This result suggests that the RMS $\left(\Psi_{s}^{\prime}\right)$ center over the tropical central Pacific is likely to be related to the frequent occurrence of the equatorial easterly waves and tropical cyclones.

The first two eigenmodes of RMS( $\left.\Psi_{\mathrm{s}}^{\prime}\right)$ are displayed in Fig. 8 to demonstrate the interannual variability of transient activity. Temporal fluctuations in the C1[RMS $\left.\left(\Psi_{s}^{\prime}\right)\right]$ (Fig. 8a) and C2[RMS( $\left.\left.\Psi_{\mathrm{s}}^{\prime}\right)\right]$ (Fig. 8c) bear a similarity to those in $\mathrm{C} 1\left[\Psi_{\mathrm{E}}(850 \mathrm{mb})\right]$ (Fig. 5c) and $\mathrm{C} 2\left[\Psi_{\mathrm{E}}(850 \mathrm{mb})\right]$ (Fig. 6c), respectively. This assessment is supported by a 0.91 correlation coefficient between $\mathrm{C} 1\left[\operatorname{RMS}\left(\Psi_{\mathrm{s}}^{\prime}\right)\right]$ and $\mathrm{C} 1\left[\Psi_{\mathrm{E}}(850 \mathrm{mb})\right]$, and 0.83 between $\mathrm{C} 2\left[\operatorname{RMS}\left(\Psi_{\mathrm{s}}^{\prime}\right)\right.$ ] and $\mathrm{C} 2\left[\Psi_{\mathrm{E}}(850 \mathrm{mb})\right]$. These results suggest that the first/second eigenmode of transient activity has a dynamic linkage with the first/second eigenmode of atmospheric circulation. In the first transient activity mode, the dominant feature of E1[RMS( $\left.\left.\Psi_{s}^{\prime}\right)\right]$ (Fig. 8b) is a belt of negative anomalies elongating from the subtropical western Pacific to the tropical central Pacific. The location of this negative anomaly belt geographically coincides with the dominant positive E1 $\left[\Psi_{\mathrm{E}}(850 \mathrm{mb})\right]$ anomaly in the western Pacific (see Fig. 5d). This relationship suggests that transient activity is suppressed (enhanced) in the anomalous high (low) region.

In the second mode, the spatial structure of E2[RMS( $\left.\left.\Psi_{s}^{\prime}\right)\right]$ (Fig. 8d) shows a meridional stratification over the North Pacific with negative anomalies in the $15^{\circ} \mathrm{N}-30^{\circ} \mathrm{N}$ band and positive anomalies in the $0^{\circ}-15^{\circ} \mathrm{N}$ band. To some extent, the negative RMS $\left(\Psi_{\mathrm{s}}^{\prime}\right)$ band matches an

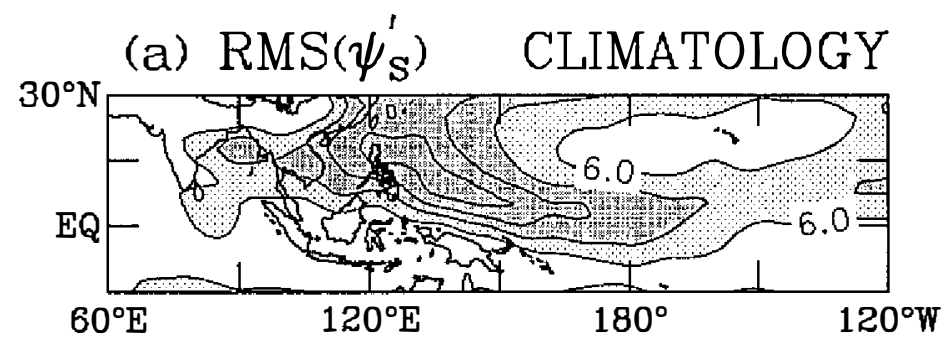

Fig. 7. The 1979-95 northern summer climatology of the synoptic-scale transient activity $\left[\operatorname{RMS}\left(\Psi_{\mathrm{s}}^{\prime}\right)\right]$. The methodology to compute $\operatorname{RMS}\left(\Psi_{\mathrm{s}}^{\prime}\right)$ is stated in the text. Contour intervals are $10^{5} \mathrm{~m}^{2} \mathrm{~s}^{-1}$. The $\operatorname{RMS}\left(\Psi_{\mathrm{s}}^{\prime}\right)$ values between $6 \times 10^{5} \mathrm{~m}^{2} \mathrm{~s}^{-1}$ and $7 \times 10^{5} \mathrm{~m}^{2} \mathrm{~s}^{-1}$ are lightly shaded and those larger than $7 \times 10^{5} \mathrm{~m}^{2} \mathrm{~s}^{-1}$ are heavily shaded. 

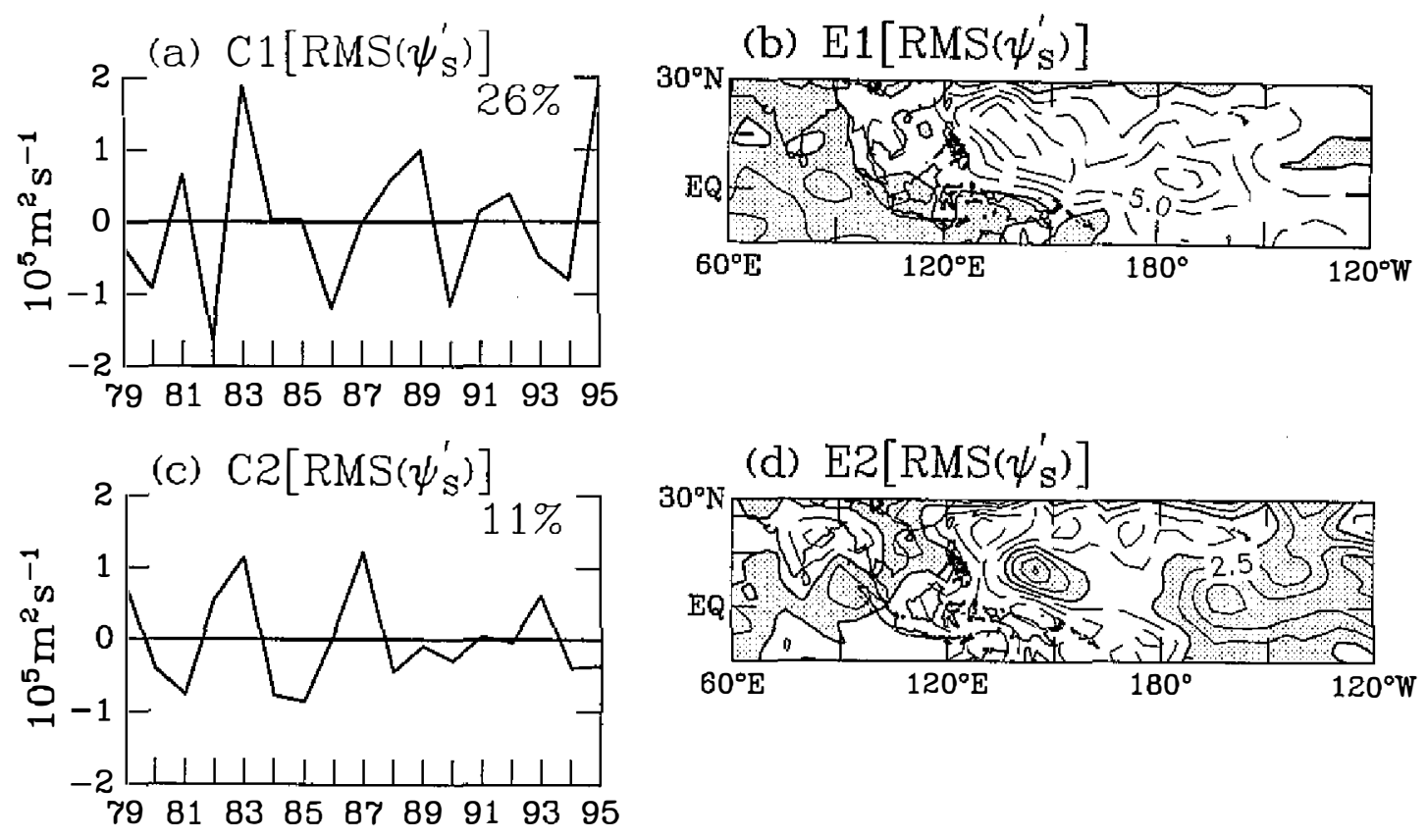

Fig. 8. The first two interannual eigenmodes of the northern summer transient activity: (a) the first eigencoefficient, (b) the first eigenvector, (c) the second eigencoefficient, and (d) the second eigenvector. In (b) and (d), contour intervals are 0.25 and positive values are shaded.

anomalous high (positive anomaly) in $\mathrm{E} 2\left[\Psi_{\mathrm{E}}(850 \mathrm{mb})\right]$ (Fig. 6d) extending from eastern Asia to the North Pacific. In the $0^{\circ}-15^{\circ} \mathrm{N}$ zone, the positive RMS $\left(\Psi_{\mathrm{s}}^{\prime}\right)$ band corresponds to an anomalous low (negative anomaly) in E2 $\left[\Psi_{\mathrm{E}}(850 \mathrm{mb})\right]$ stretching from the central Pacific westward to the equatorial western Pacific. Similar to the first mode, the E2[RMS $\left.\left(\Psi_{\mathrm{s}}^{\prime}\right)\right]$ and $\mathrm{E} 2\left[\Psi_{\mathrm{E}}(850 \mathrm{mb})\right]$ patterns demonstrate that transient activity tends to enhance (weaken) in an anomalous low (high) background. In addition to the Pacific region, the first two RMS ( $\Psi_{\mathrm{s}}^{\prime}$ ) modes both show a random pattern with weaker intensity over the Indian monsoon region. This result reveals that the interannual variation of transient activity is more significant in the Pacific than in the Indian monsoon region.

\section{CLIMATOLOGY AND INTERANNUAL VARIABILITY OF HYDROLOGICAL PROCESSES}

The hydrological characteristics of the interannual variability of the atmospheric system are analyzed in this section. Hydrological processes of the atmosphere are often depicted by a water-budget equation:

$$
\partial \mathrm{W} / \partial \mathrm{t}+\nabla \bullet \mathrm{Q}=\mathrm{E}-\mathrm{P}
$$


where $\mathrm{W}, \mathrm{Q}, \mathrm{E}$, and $\mathrm{P}$ are the total atmospheric precipitable water, vertically-integrated water vapor flux, evaporation, and precipitation, respectively. Deser and Wallace (1990) pointed out that in the El Niño phases, the precipitation anomaly over the tropical central Pacific is maintained primarily by the convergence of water vapor flux, rather than in-situ evaporation. Simmonds et al. (1999) also found that over China, the dominant terms in the interannual variability of the summer hydrological processes are atmospheric moisture convergence and precipitation. In view of theses findings, we thus focus our analyses of the hydrological processes on precipitation, divergence of water vapor flux $(\nabla \bullet \mathrm{Q})$, and precipitable water.

The northern summer climatologies of $P, \nabla \bullet Q$, and $W$ are displayed in Fig. 9. The $P$ pattern (Fig. 9a) can be divided into several heavy precipitation sectors. One sector covers the Asian monsoon region, with maximum centers over the Arabian Sea, Bay of Bengal, and South China Sea. Heavy precipitation spreads eastward along the tropical western Pacific east
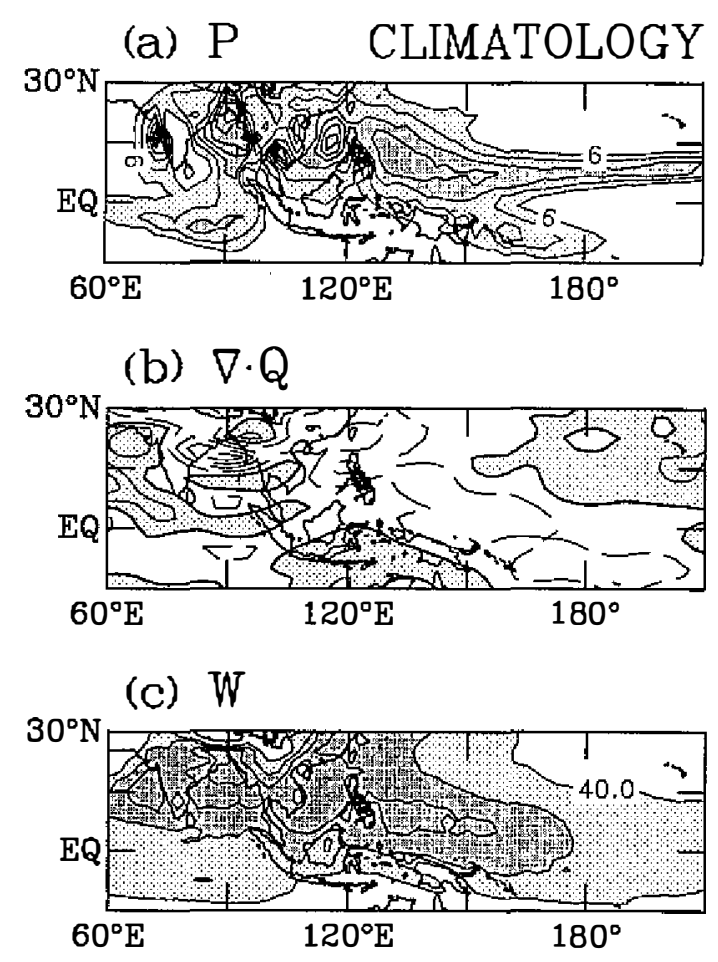

Fig. 9. The 1979-95 northern summer climatologies of the hydrological variables: (a) precipitation $(\mathrm{P})$, (b) divergence of the water vapor flux $(\nabla \bullet \mathrm{Q})$, and (c) precipitable water (W). In (a), contour intervals are $2 \mathrm{~mm} /$ day. The $\mathrm{P}$ values between $6 \mathrm{~mm} /$ day and $10 \mathrm{~mm} /$ day are lightly shaded and those larger than $10 \mathrm{~mm} /$ day are heavily shaded. In (b), contour intervals are 3 $\mathrm{mm} /$ day and positive values are shaded. In (c), contour intervals are 5 $\mathrm{Kgm}^{-2}$. The W values between $40 \mathrm{Kgm}^{-2}$ and $45 \mathrm{Kgm}^{-2}$ are lightly shaded and those larger than $45 \mathrm{Kgm}^{-2}$ are heavily shaded. 
of the Philippines and extends farther to form two rain belts over the equatorial central Pacific: the ITCZ and the South Pacific Convergence Zone (SPCZ). To supply moisture for the aforementioned heavy precipitation, $\nabla \bullet \mathrm{Q}$ (Fig. 9 b) exhibits a convergence of water vapor flux (negative pattern) in the Bay of Bengal, South China Sea, tropical western Pacific, and SPCZ. Water vapor also converges into the central-Pacific ITCZ, except that its intensity is quite weak. Following the water vapor convergence, large amounts of atmospheric moisture, as interpreted from the precipitable water field in Fig. 9c, accumulate in heavy precipitation regions and provide the moisture source for precipitation. This relationship leads to a resemblance in spatial structure between the $\mathrm{P}$ and $\mathrm{W}$ fields. The above hydrological processes reveal that the convergence of water vapor flux increases atmospheric moisture content to maintain heavy precipitation.

The interannual variability of hydrological processes is portrayed by the first two eigenmodes of $\mathrm{P}, \nabla \bullet \mathrm{Q}$, and $\mathrm{W}$ fields. The first eigenmodes of these fields are shown in Fig. 10. For the temporal variation, time series of $\mathrm{Cl}(\mathrm{P})$ (Fig. 10a), $\mathrm{Cl}(\mathrm{\nabla} \bullet \mathrm{Q})$ (Fig. 10c), and $\mathrm{C} 1$ (W) (Fig. 10e) contain common features such as large positive phases in the summers of 82,87 and 91 and large negative phases in those of 84,85 and 88 . These temporal features are consistent with that of C1(SST) (see Fig. 2a), except for a discrepancy in the phase of the summer of 83 in which $\mathrm{Cl}$ (SST) contained a positive maximum. Nevertheless, a large positive phase is found in $\mathrm{C} 1(\mathrm{P})$, but there is a minor positive phase in $\mathrm{C} 1(\mathrm{~W})$ and even a minor negative phase in $\mathrm{C} 1(\nabla \bullet \mathrm{Q})$. The above differences suggest that in the El Niño summer of 83 variations in SST and moisture fields, such as $\mathrm{W}$ and $\nabla \bullet \mathrm{Q}$, have a relationship somehow different from those happening in other major El Niño summers. In spite of the phase discrepancy in the summer of 83 , the correlation coefficients between $\mathrm{C} 1(\mathrm{SST})$ and $\mathrm{C} 1(\mathrm{P}), \mathrm{C} 1(\nabla \bullet \mathrm{Q})$, and $\mathrm{C} 1$ (W) are $0.86,0.78$, and 0.84 , respectively. These high correlation coefficients suggest that the first eigenmodes of $\mathrm{P}, \nabla \bullet \mathrm{Q}$, and $\mathrm{W}$ are in connection with the first SST eigenmode, which represents the interannual SST variability induced by alternations between the El Niño and La Niña events.

In the spatial structure, the E1(P) pattern (Fig. 10b) is noticeable by two major negative $\mathrm{P}$ anomalies over the southeast-Asian maritime continents and the northwestern Pacific east of the Philippines and Taiwan. Between these two negative anomalies, a major positive $P$ anomaly is located over the equatorial central Pacific with a center west of the date line. The negative $P$ anomaly over the southeast-Asian maritime continents is accompanied by a divergence of water vapor flux as indicated by a positive center in $\mathrm{El}(\nabla \bullet \mathrm{Q})$ (Fig. 10d). It is also linked to a negative center in E1(W) (Fig. 10f) which indicates a decrease in the atmospheric water vapor content. A similar situation occurs over the northwestern Pacific east of Taiwan. A divergent (positive) $\mathrm{E} 1(\nabla \bullet \mathrm{Q})$ anomaly and a decreased (negative) $\mathrm{E} 1(\mathrm{~W})$ anomaly accompany the negative $P$ anomaly there. However, the intensity of the $E 1(\nabla \bullet Q)$ anomaly and E1 (W) anomaly over the northwestern Pacific is weaker than that over the southeast-Asian maritime continents. For the major positive $\mathrm{P}$ anomaly over the tropical central Pacific, it is located in an environment with extra water vapor content (positive E1(W) center in Fig. 10f) due to the convergence of water vapor flux into to this region (negative $\mathrm{E} 1(\nabla \bullet \mathrm{Q})$ center in Fig. $10 \mathrm{~d})$. The above analyses portray the following dynamic relationship between $\mathrm{E} 1(\mathrm{P}), \mathrm{E} 1(\nabla \bullet \mathrm{Q})$ and E1(W). The positive (negative) precipitation anomalies are maintained by an increase (a 

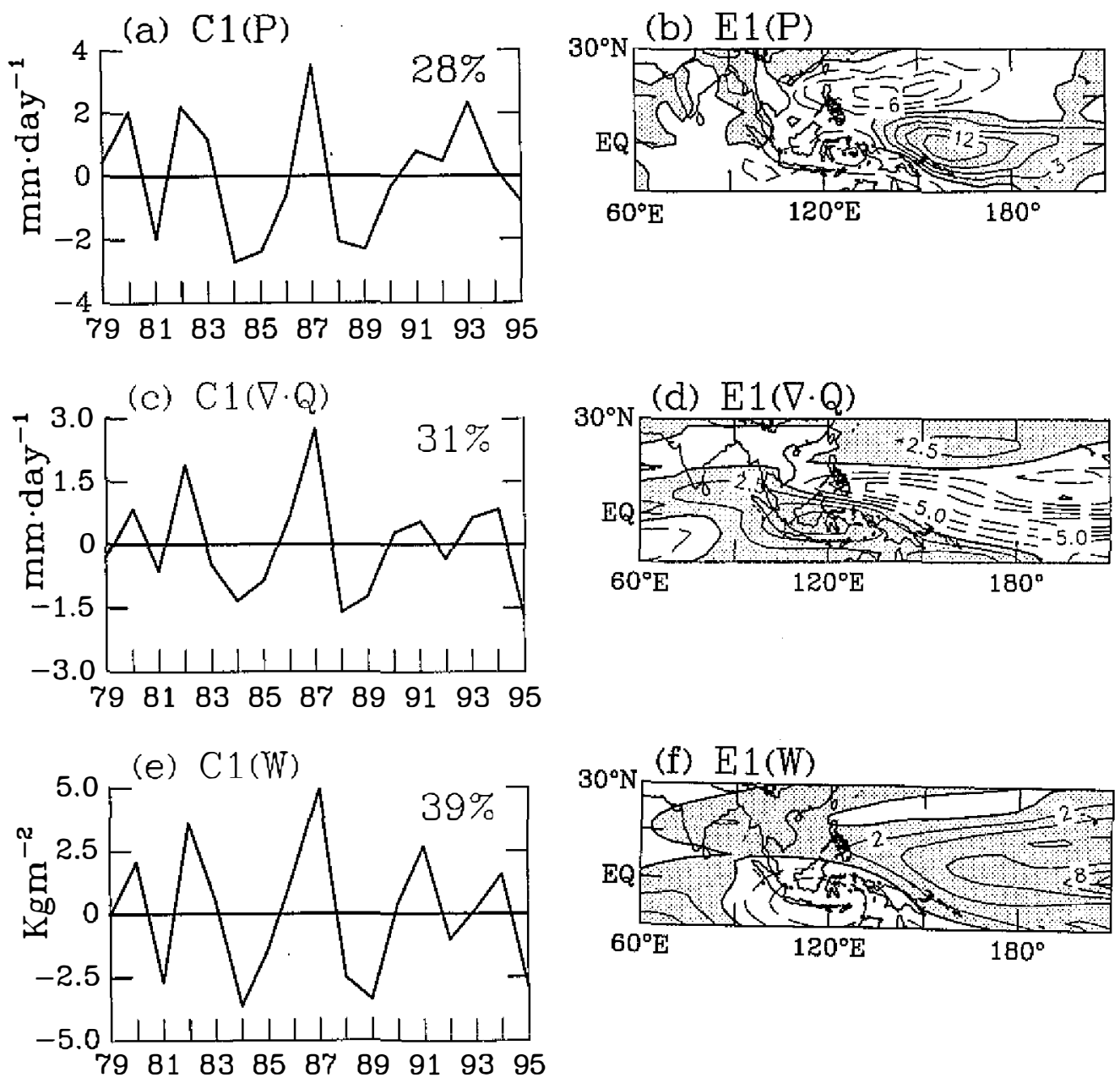

Fig. 10. The first eigencoefficient/eigenvector of the northern summer interannual modes of the hydrological processes: (a)/(b) precipitation, (c)/(d) divergence of the water vapor flux, and (e)/(f) precipitable water. Contour intervals are (b) 0.25 , (d) 0.25 , and (f) 0.15 . All positive values in the eigenvector plots are shaded.

decrease) in atmospheric water vapor following the convergence (divergence) of water vapor flux. These dynamic relationships among the interannual hydrological modes are consistent with those found from the climatological modes.

Since the first $\mathrm{P}$ mode is related to the first SST mode, it is of interest to compare the El (P) pattern with the spatial patterns of the other interannual modes associated with the first SST mode, such as the OLR anomaly in Fig. 3c, E2[RMS $\left(\Psi_{\mathrm{s}}^{\prime}\right)$ ] in Fig. 8d, and [ $\Psi_{\mathrm{E}}(850 \mathrm{mb})$ ] in Fig. 6d. Over the northwestern Pacific, the negative E1(P) anomalies east of the Philippines are in accordance with the suppression of the tropical convection (positive OLR anomaly) and 
transient activity (negative E2[RMS $\left.\left(\Psi_{\mathrm{s}}^{\prime}\right)\right]$ anomaly). All of these anomalies are located in an $850 \mathrm{mb}$ anomalous high background (positive E2[ $\left.\Psi_{\mathrm{E}}(850 \mathrm{mb})\right]$ anomaly). A similar spatial relationship between the aforementioned fields occurs over the southeast-Asian maritime continents where another major negative $\mathrm{E} 1(\mathrm{P})$ anomaly exists. As for the positive $\mathrm{E} 1(\mathrm{P})$ anomaly, the one over the tropical central Pacific west of the date line matches well with the enhanced tropical convection (negative OLR anomaly). However, the enhanced transient activity (positive $\operatorname{E} 2\left[\operatorname{RMS}\left(\Psi_{s}^{\prime}\right)\right]$ anomaly) and an anomalous low (negative E2[ $\left.\Psi_{\mathrm{E}}(850 \mathrm{mb})\right]$ anomaly) are located somewhat to the north of this positive E1(P) anomaly. The above spatial relationships indicate that the hydrological fields exhibit a clear dynamic connection with the large-scale convection, atmospheric circulation, and transient activity in the interannual time scale.

In the second set of hydrological modes, the temporal fluctuations of C2(P) (Fig. 11 a), C2 $(\nabla \bullet \mathrm{Q})$ (Fig. 11c), and C2(W) (Fig. 11e) are not as coherent with one another as those found from the first modes. However, these time series still contain some common features. They all undergo evident phase changes between the developing and decaying periods of the major El Niño events. For the 82/4-83/7 and 86/8-88/2 El Niño events, these eigencoefficient time series vary from negative phases in the summers of 82 and 86 into positive phases in those of 83 and 88. For the third major EI Niño event during the period 91/3-92/7, changes in eigencoefficient phase from a negative state in the summer of 91 into a positive state in that of 92 occur in $C 2(\mathrm{P})$ and $\mathrm{C} 2(\nabla \bullet \mathrm{Q})$, but not in $\mathrm{C} 2(\mathrm{~W})$. Note that the phase change around the major El Niño events is the salient feature of the second SST mode. We thus compute correlation coefficients between the second SST mode and the second hydrological modes to assess the degree of temporal coherence for these modes. The correlation coefficients between $\mathrm{C} 2$ (SST) and $\mathrm{C} 2(\mathrm{P}), \mathrm{C} 2(\nabla \bullet \mathrm{Q})$, and $\mathrm{C} 2(\mathrm{~W})$ are $0.70,0.69$, and 0.77 , respectively. Since the correlation coefficients are so high (about 70\%), it is legitimate to consider that the second set of hydrological modes correspond to the interannual SST variability resulting from contrasts between the developing and decaying stages of the major ENSO events, as interpreted from the second SST mode.

In the spatial structure, the salient pattern in E2(P) (Fig. 11b) is a major negative anomaly over the western Pacific with a center east of the Philippines. To the southwest of this negative $\mathrm{P}$ anomaly, there is a positive $\mathrm{P}$ anomaly centered at the southeast-Asian maritime continent. In the moisture fields, a north-south stratified pattern stands out clearly in E2( $\nabla \bullet Q)$ (Fig. 11d) and E2(W) (Fig. 11f). This stratified pattern suggests that water vapor is divergent (positive pattern) out of the North Pacific in the $10^{\circ} \mathrm{N}-25^{\circ} \mathrm{N}$ zone in connection with the decrease (negative anomaly) in precipitable water and precipitation. Water vapor is then transported southward to converge (negative pattern) over the equatorial zones in the vicinity of the southeast-Asian maritime continent where positive anomalies of precipitable water and precipitation are located. The above spatial relationships indicate that water vapor is convergent (divergent) to increase (reduce) the atmospheric water vapor content and leads to a favorable condition for the enhancement (suppression) of precipitation. There is no doubt that the mutual dynamic relationship between the second modes of hydrological fields is consistent with that found from the first modes.

A further comparison is made between anomalies of precipitation, OLR, and atmospheric flows. Let us take the major negative E2(P) center east of the Philippines as the example. This 

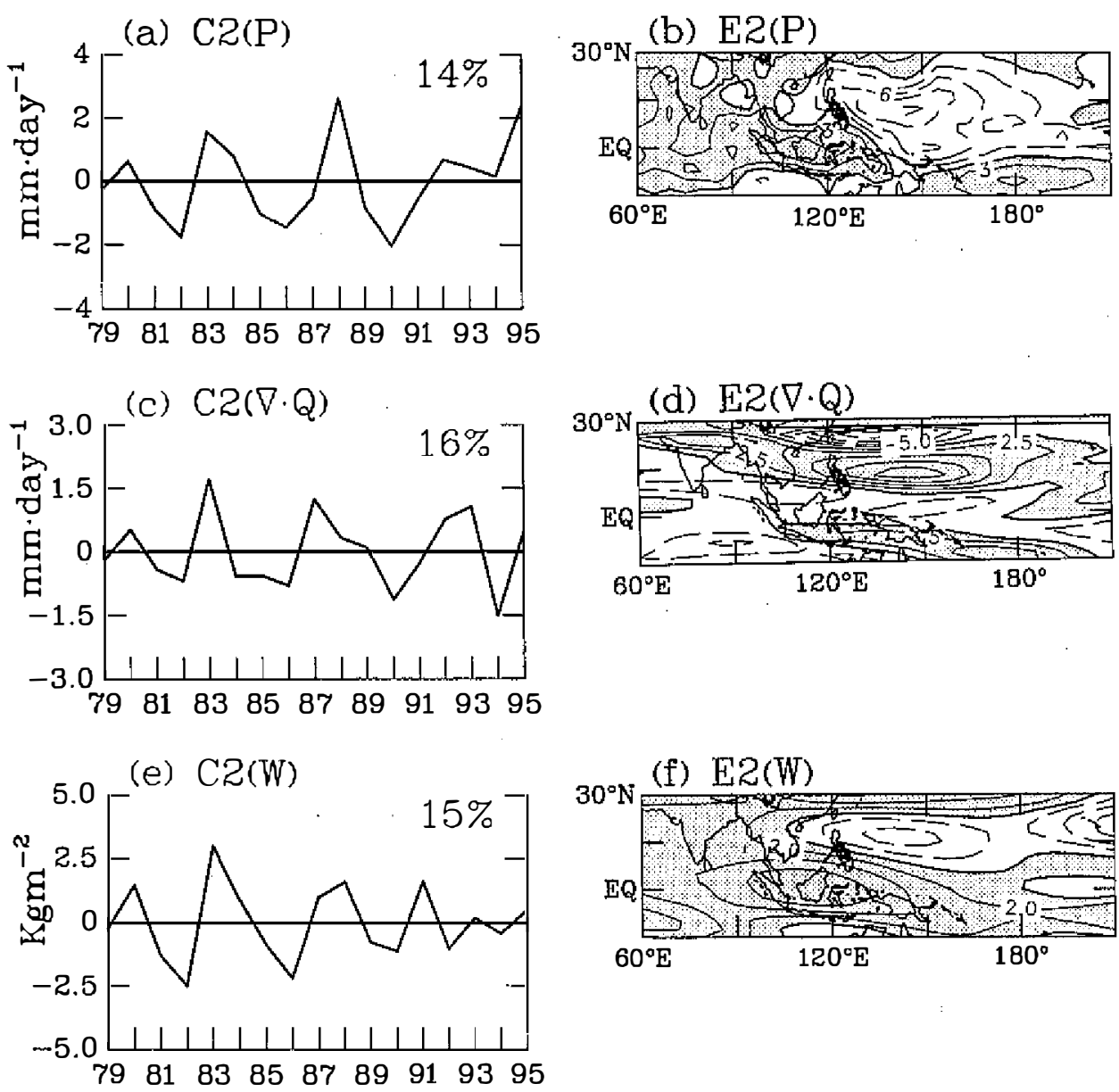

Fig. 11. As in Fig. 10, except for the second interannual modes of the northern summer hydrological processes.

E2(P) center is embedded in an anomalous high background (positive E1 [ $\left.\Psi_{\mathrm{E}}(850 \mathrm{mb})\right]$ center in Fig. 5d) and is accompanied by the suppression in transient activity (negative E1[RMS $\left(\Psi_{\mathrm{s}}^{\prime}\right)$ ] center in Fig. 8b) and tropical convection (positive OLR anomaly in Fig. 3d). This result suggests a systematic linkage between the second set of hydrological modes and the interannual modes of the atmospheric flows and large-scale convection activity.

\section{CONCLUDING REMARKS}

In this study, we have analyzed the dynamic and hydrological characteristics of the interannual variability of the northern summer (June-August) ocean-atmosphere system in the Asian-Pacific region for the period 1979-95. As indicated by the temporal and spatial features of the interannual SST anomalies, there are two types of interannual modes in the northern 
summer ocean-atmosphere system. The first type is characterized by the interannual variability associated with variations of the mature phase of the ENSO events. Its major temporal fluctuation is an alternation between the El Niño and La Niña events. Its salient spatial pattem is an elongated warm (cold) SST anomaly over the eastern-Pacific Niño-3 region during the El Niño (La Niña) event. The second type is characterized by the interannual variability induced by contrasts between the developing and decaying stages of the ENSO events. Its salient feature is warm (cold) SST anomalies in the tropical central Pacific during the developing stage of the El Niño (La Niña) event, and warm (cold) SST anomalies near the Peruvian coast during the decaying stage.

These two interannual SST modes exert systematic impacts on the atmosphere. Regarding the vertical motion, tropical convection and the upward branch of the Walker circulation overlying the warm (cold) SST anomalies become intensified (suppressed). In the western Pacific, the centers of tropical convection anomalies spatially coincide with the centers of SST anomalies and the major branch of Walker circulation anomalies. In the central and eastern Pacific, the anomalous convection centers reside westward from the centers of SST anomalies and the major branch of Walker circulation anomalies.

Regarding the horizontal motion, the lower-tropospheric planetary-scale circulation anomalies corresponding to the first SST mode possess a spatial pattern largely opposite to the climatological circulation. It shows that the Asian low and Pacific subtropical high are weakened (strengthened) and accompanied by weaker (stronger) tropical monsoon westerlies and $\mathrm{Pa}$ cific trade winds during the mature El Niño (La Niña) phase. The major circulation anomalies corresponding to the second SST mode show an anomalous low (high) centered in the western Pacific during the developing (decaying) phase of the El Niño event. In accordance with this circulation anomaly, anomalous westerlies prevail in the tropical western Pacific during the developing stage of the El Niño event, and the tropical trade winds dominate during the decaying stage.

Regarding the hydrological characteristics, water vapor flux converges toward the convection-enhanced region to increase the atmospheric precipitable water and thus maintain the local positive precipitation anomaly. The enhancements of precipitation and tropical convection are accompanied by the enhancement of transient activity. The above phenomena are embedded in a convection-favorable large-scale environment like an anomalous lower-tropospheric low. On the other hand, the divergence of water vapor flux, negative precipitation anomaly, suppressed tropical convection, and weaker transient activity are found for the region of an anomalous lower-tropospheric high.

Based upon analysis results in this study, we construct a schematic diagram (Fig. 12) to illustrate the framework of the interannual variability of the northern summer ocean-atmosphere system in the Asian-Pacific region. In the ocean sector, SST changes related to ENSO phenomena constitute the major variability in the first two dominant interannual modes. These interannual SST modes then exert systematic impacts on the atmospheric system due to the ocean-atmosphere coupling process, which is inferred from vertical motions associated with the tropical convection and Walker circulation. Following the coupling process, the dynamic and hydrological processes of the atmospheric system exhibit systematic linkages with the interannual SST variability. In the dynamic processes, the planetary-scale atmospheric 


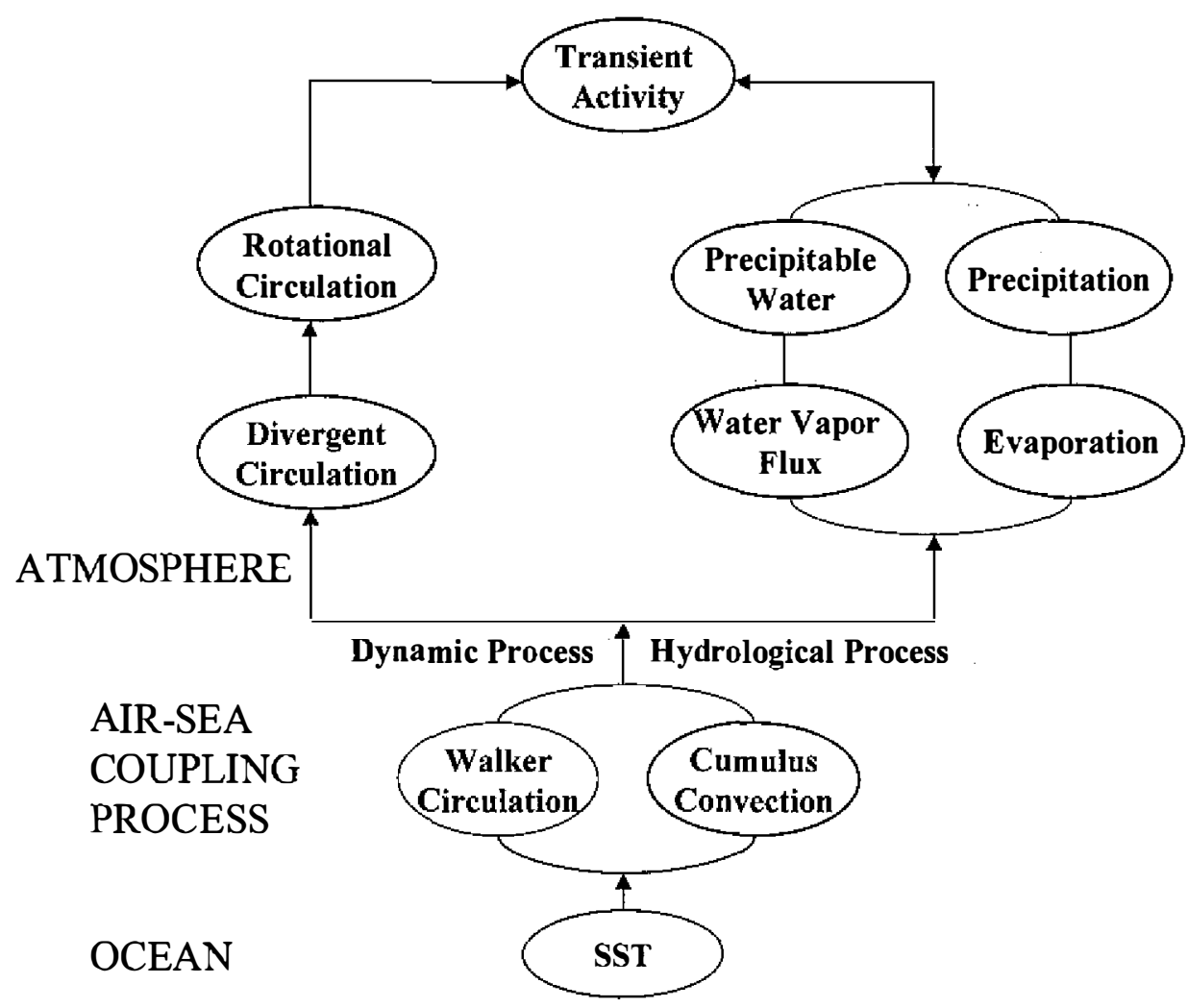

Fig. I2. A schematic diagram to illustrate the possible dynamic framework for the interannual variability of the northern summer ocean-atmosphere system in the Asian-Pacific region. This diagram is constructed based upon analyses in this study.

circulation, such as velocity potential and streamfunction, undergo very coherent interannual variability with the SST changes. The planetary-scale circulation anomalies provide a largescale environment for the synoptic-scale transient activity to evolve. Thus, the transient activity exhibits rather coherent interannual variability with the two dominant ocean-atmosphere interannual modes. In the hydrological processes, the interannual changes of precipitation and moisture fields are found to be closely linked with the interannual variability of the large-scale tropical convection. Our analysis also suggests a possible connection between the hydrological processes and dynamic processes. It shows that the enhanced (reduced) precipitation anomalies are accompanied with the intensified (suppressed) transient activity. In fact, heavy precipitation in the low latitudes is of ten brought in by the moisture-rich transient disturbances, such as tropical cyclones and equatorial waves. Matthews and Kiladis (1999) also demonstrated thatduring the ENSO events, transient activity and ropical convection (or precipitation) in the transient time scale both show coherent responses to the changes of the large-scale environments. Thus, it is likely that the dynamic processes and hydrological processes of the 
atmospheric system can connect together through the tropical transient activity and its accompanying precipitation.

We further construct a table to summarize our analysis results. All atmospheric modes related to the first and second SST modes are separated into two groups and listed in Table 1. This table shows an interesting relationship: the atmospheric modes related to the first (second) SST mode are the most (second most) dominant modes in the hydrological fields (such as $\mathrm{P}$, $\nabla \bullet \mathrm{Q}$, and $\mathrm{W}$ ), but the second most (most) dominant modes in the dynamic fields (such as $\chi_{\mathrm{E}}$ ( $850 \mathrm{mb}), \Psi_{\mathrm{E}}(850 \mathrm{mb})$, and RMS ( $\left.\Psi_{\mathrm{s}}^{\prime}\right)$. In other words, the most significant interannual modes in the atmospheric flow system are related to the second SST mode, even if the intensity of the second SST mode is only one third of the first SST mode. Recall that the first SST mode contains significant anomalies in the tropical eastern Pacific and no clear pattern in the western Pacific [see E1(SST) in Fig. 2c]. On the other hand, the second SST mode has organized patterns in the South China Sea-western Pacific region [see E2(SST) in Fig. 2d]. The above discrepancy in SST spatial structure implies that the interannual variability of the northern summer atmospheric flow system in the tropical Asian-Pacific region is more sensitive to local SST variations near the western Pacific (as inferred from the second SST mode), than it

Table 1. Two sets of interannual modes of the northern summer ocean-atmosphere system and the correlation coefficients between any two selected interannual modes in each set to indicate their dynamic connection

\begin{tabular}{|c|c|c|}
\hline & FIRST SET & SECOND SET \\
\hline COMPONENTS & First SST mode & Second SST mode \\
\hline & Second $\chi_{E}(850 \mathrm{mb})$ mode & First $\chi_{\mathrm{E}}(850 \mathrm{mb})$ mode \\
\hline & Second $\psi_{\mathrm{E}}(850 \mathrm{mb})$ mode & First $\psi_{\mathrm{E}}(850 \mathrm{mb})$ mode \\
\hline & Second RMS $\left(\psi_{\mathrm{S}}^{\prime}\right)$ mode & First RMS $\left(\psi_{S}^{\prime}\right)$ mode \\
\hline & First $P$ mode & Second P mode \\
\hline & First $(\nabla \bullet Q)$ mode & Second $(\nabla \bullet Q)$ mode \\
\hline & First $\mathrm{W}$ mode & Second W mode \\
\hline \multicolumn{3}{|c|}{ Correlation coefficient } \\
\hline SST $\sim \chi_{E}(850 \mathrm{mb})$ & 0.77 & 0.82 \\
\hline SST $\sim \psi_{E}(850 \mathrm{mb})$ & 0.83 & 0.87 \\
\hline$\psi_{\mathrm{E}}(850 \mathrm{mb}) \sim \mathrm{RMS}\left(\psi_{\mathrm{S}}^{\prime}\right)$ & 0.83 & 0.91 \\
\hline SST $\sim P$ & 0.86 & 0.70 \\
\hline SST $\sim \nabla \bullet Q$ & 0.78 & 0.69 \\
\hline SST $\sim \mathrm{W}$ & 0.84 & 0.77 \\
\hline
\end{tabular}


is to remote SST variations in the eastern Pacific (as inferred from the first SST mode).

Also listed in Table 1 are the correlation coefficients between any two fields selected from the same group. Correlation coefficients between the first SST mode and its associated atmospheric modes reach a level of about 0.8 . For the second SST mode, correlation coefficients with the atmospheric modes are above 0.8 in the dynamic fields, but these are lowed to around 0.7 in the hydrological fields. These correlation coefficients are indeed high enough and demand a reasonable explanation. Recall that both SST modes represent the tropical SST variability associated with the ENSO phenomena. The tropical SST variability adjusts the tropical vertical motions and thus affects the moisture transport between the atmosphere and ocean. Variability in the moisture transport then leads to variability in the atmospheric water vapor content as well as the atmospheric hydrological processes. Therefore, through the moisture exchange processes between the ocean and atmosphere, the interannual SST anomalies and the atmospheric hydrological fields are likely to be closely linked, which explains the high correlation coefficients between these two fields . Meanwhile, the moisture transport is a key factor in deciding the tropical precipitation. Since the latent heat release of tropical precipitation forms the primary heat source for atmospheric motions, the ropical SST variability can change the atmospheric heating distribution by affecting moisture transport and its associated precipitation anomaly. Following the redistribution in atmospheric heating, the atmospheric flow fields (such as atmospheric circulation and transient activity) can change in accordance with the SST anomaly. These processes explain the high correlations between the interannual SST modes and atmospheric dynamic fields.

One interesting way to utilize the result of this study is to compare it with the interannual variability of the northern winter ocean-atmosphere system. Let us take the spatial pattern as an example for comparison. During the El Niño period, the tropical SST anomalies exhibit a similar pattern in winter and summer: a strong warm anomaly along the eastern Pacific and a weak cold anomaly in the western Pacific. As mentioned before, this longitudinal pattern is largely opposite to the northern summer SST climatology. Following the phase reversal in tropical SST anomalies, the summer $\Psi_{\mathrm{E}}(850 \mathrm{mb})$ anomaly exhibits a spatial pattern primarily opposite to the summer $\Psi_{\mathrm{E}}(850 \mathrm{mb})$ climatology, as shown by the second $\Psi_{\mathrm{E}}(850 \mathrm{mb})$ mode in this study. In winter, the maximum center of the northern winter SST climatology is located in the central Pacific which forms a warm pool in the vicinity of the date line (e.g., Philander 1990), while the cold tongue still remains in the eastern Pacific. There thus exists a phase shift between the maximum centers of the northern winter SST climatology (i.e., central Pacific) and the El Niño SST anomaly (i.e., eastern Pacific). Such a phase shift is not large enough to be out of phase as in the case of the northern summer. Following the phase shift in tropical SST patterns, a phase shift occurs between the climatology and interannual anomaly of the northern winter atmospheric circulation. Rogers and Raphael (1992) and others have shown that the northern winter $500 \mathrm{mb}$ geopotential high anomaly during the El Niño period contains anomalous centers surrounding the climatological ridges and troughs, instead of overlapping them. The above comparisons reveal that the spatial patterns of the El Niño-related anomalies and the climatology are more or less opposite in the northern summer season, but only in certain phase shifts in the northern winter season.

This study analyzes only some selected processes of the interannual variability of the 
northern summer ocean-atmosphere system. Many more processes of this interannual variability system, including radiation processes and ocean dynamics, still need further analysis. This study is regarded as a pilot study with which we hope to attract more research attention to study the northern summer ocean-atmosphere system.

Acknowledgements This study was sponsored by the Short-Term Climate Prediction Project of the Central Weather Bureau, Taiwan. We wish to thank Director-General Shinn-Liang Shieh, Dr. Ming-Deng Chang, and Prof. Chi-Pei Chang for their encouragement and support for this project. Thanks also go to the anonymous reviewers for their comments and Mr. Joel A. Newson for editorial assistance.

\section{REFERENCES}

Blackmon, M. L., J. E. Geisler, and E. J. Pitcher, 1983: A general circulation model study of January climate anomaly patterns associated with interannual variation of equatorial Pacific sea surface temperatures. J. Atmos. Sci., 40, 1410-1425.

Blackmon, M. L., J. M. Wallace, N.-C. Lau, and S. L. Mullen, 1977: An observational study of the Northem Hemisphere wintertime circulation. J. Atmos. Sci., 34, 1040-1053.

Chen, T.-C., and J.-M. Chen, 1990: A note on the maintenance of stationary eddies with the streamfunction budget analysis. J. Atmos. Sci., 47, 2818-2824.

CLIVAR Science Plan, 1995: A study of climate variability and predictability. WCRP-89, WMO/TD-No. 690, 107 pp. [Available from WCRP/WMO, Case Postal 2300, CH1211, Geneva 2, Switzerland.]

Deser, C., and J. M. Wallace, 1990: Large scale atmospheric circulation features of warm and cold episodes in the tropical Pacific. J. Climate, 3, 1254-1281.

Deser, C., and M. L. Blackmon, 1993: Surface climate variations over the North Atlantic Ocean during winter:1900-1989. J. Climate, 6, 1743-1753.

Gill, A. E., 1980: Some simple resolutions for heat-induced tropical circulation. Quart. $J$. Roy. Meteor. Soc., 106, 447-462.

Graham, N. E., T. P. Barnett, R. White, M. Ponater, and S. Schubert, 1994: On the roles of tropical and midlatitudal SSTs in forcing the interannual to interdecadal variability in the winter Northern Hemisphere circulation. J. Climate, 7, 1416-1441.

Holton, J. R., 1992: An introduction to dynamic meteorology. 3rd. ED. Academic Press. 507 pp. ISBN-0-12-354355-X.

Horel, J. D., and J. M. Wallace, 1981: Planetary-scale atmospheric phenomena associated with the Southern oscillation. Mon. Wea. Rev., 109, 813-829.

Jones, P. D., 1994: Hemispheric surface air temperature variations: A reanalysis and an update to 1993. J. Climate, 11, 1794-1802.

Ju, J., and J. Slingo, 1995: The Asian summer monsoon and ENSO. Q. J. R. Meteor. Soc., 121, 1133-1168.

Kalnay, E., and coauthors, 1996: The NCEP/NCAR 40-year reanalysis project, Bull. Ame. Meteor. Soc., 77, 437-471. 
Keen, R. A., 1982: The role of cross-equatorial cyclone pairs in the Southern Oscillation. Mon. Wea. Rev., 110, 1405-1410.

Krishnamurti, T. N., 1971: Tropical east-west circulation during the northern summer. J. Atmos. Sci., 28, 1342-1347.

Lau, K.-M., C.-H. HO, and I.-S. Kang, 1998: Anomalous atmospheric hydrological processes associated with ENSO: Mechanisms of hydrological cycle-radiation interaction. $J$. Climate, 11, 800-815.

Lau., N.-C., 1988: Variability of the observed midlatitude storm tracks in relation to low frequency changes in the circulation pattern. J. Atmos. Sci., 45, 2718-2743.

Lau, N.-C., and M. J. Nath, 1994: A modeling study of the relative roles of tropical and extratropical SST anomalies in the variability of global atmosphere-ocean system. $J$. Climate, 7, 1184-1207.

Li, C., and M. Yanai, 1996: The onset and interannual variability of the Asian summer monsoon in relation to land-sea thernal contrast. J. Climate, 9, 358-375.

McBride, J. L., 1995: 'Tropical Cyclone Formation' in Global Perspectives on Tropical Cyclone edited by Russel L. Elsberry. WMO/TD-No. 693, 289 pp. [Available from WMO, Case Postal 2300, CH-1211, Geneva 2, Switzerland.]

Matsuno, T., 1966: Quasi-geostrophic motions in equatorial areas. J. Meteor. Soc. Japan., 2, 25-43.

Matthews, A. J., and G. N. Kiladis, 1999: Interactions between ENSO, transient circulation, and tropical convection over the Pacific. J. Climate, 12, 3062-3086.

Newell, R. E., J. W. Kidson, D. J. Vincent, G. J. Boer, 1974: The general circulation of the tropical atmosphere. MIT Press, 370 pp. ISBN 0-26-14029-9.

Nitta, T., and T. Motoki, 1987: Abrupt enhancement of convective activity and low-level westerly burst during the onset of the 1986-87 El Niño. J. Meteor. Soc. Japan, 65, 497506.

Philander, S. G., 1990: El Niño, La Niña, and the Southern Oscillation. Academic Press, 293pp. ISBN 0-12-553235-0.

Rasmusson, E. M., and T. H. Carpenter, 1982: Variation in tropical sea surface temperature and surface wind fields associated with the Southern Oscillation/El Niño. Mon. Wea. Rev., 110, 354-384.

Rogers, J. C., and M. N. Raphael, 1992: Meridional eddy sensible heat fluxes in the extremes of the Pacific/Northern American teleconnection pattern. J. Climate, 5, 127-139.

Sadeshmukh, P. D., and B. J. Hoskins, 1988: The generation of global rotational flow by steady, idealized tropical divergence. J. Atmos. Sci., 45, 1228-1251.

Simmonds, I., D. Bi, P. Hope, 1999: Atmospheric water vapor flux and its association with rainfall over China in summer. J. Climate, 12, 1353-1367.

Trenberth, K. E., 1997: The definition of EI Niño. Bull. Ame. Meteor. Soc., 78, 2771-2777.

Wallace, J. M., and C.-P. Chang, 1969: Spectrum analysis of large-scale wave disturbance in the tropical lower troposphere. J. Atmos. Sci., 26, 1010-1025.

Wang, B., 1992: The vertical structure and development of the ENSO anomaly mode during 1979-1989. J. Atmos. Sci., 49, 698-712. 
Wang, B., R. Wu, and X. Fu, 2000: Pacific-East Asian teleconnection: How does ENSO affect East Asian climate? J. Climate, 13, 1517-1536.

Xie, P., and P. A. Arkin, 1996: Analyses of global monthly precipitation using gauge observations, satellite estimates, and numerical model predictions. J. Climate, 9, 840858.

Yamagata, T., and Y. Masumoto, 1989: A simple ocean-atmosphere coupled model of the origin of a warm ENSO event. Phil. Trans. Roy., 329, 225-236.

Yang, S., and K.-M. Lau, 1998: Influences of sea surface temperature and ground wetness on Asian summer monsoon. J. Climate, 11: 3230-3246. 